\title{
IMPLEMENTAÇÃO DE MÉTODO ANALÍTICO PARA DETERMINAÇÃO DE RESÍDUOS DE ORGANOFOSFORADOS EM LEITE POR CROMATOGRAFIA A GÁS COM DETECTOR FOTOMÉTRICO DE CHAMA
}

Lucia Helena Pinto Bastos*, Adherlene Vieira Gouvêa, Fabíola Málaga, Maria Helena Wohlers Morelli Cardoso, Silvana do Couto Jacob e Armi Wanderley da Nóbrega

Departamento de Química, Instituto Nacional de Controle de Qualidade em Saúde, Fundação Oswaldo Cruz, Av. Brasil, 4365, 21045-900 Rio de Janeiro - RJ, Brasil

Recebido em 23/9/11; aceito em 14/2/12; publicado na web em 30/4/12

\begin{abstract}
DEVELOPMENT AND VALIDATION OF A METHOD FOR ANALYSIS OF ORGANOPHOSPHATE RESIDUES IN MILK USING GAS CHROMATOGRAPHY WITH FLAME PHOTOMETRIC DETECTION. This paper regards the implementation of the QuEChERS method for the analysis by GC-FPD of 53 different pesticides from the organophosphate class, in whole UHT and pasteurized milk. Selectivity, linearity, repeatability, recovery and limits of detection and quantification were evaluated. Of all pesticide recoveries, 51 were considered satisfactory since the values ranged from 70 to $120 \%$ with RSD < $20 \%$. The quantification limits ranged from 0.005 to $0.4 \mathrm{mg} \mathrm{kg}^{-1}$. The QuEChERS method was suitable for determination of 52 pesticides, presenting several advantages - quick, cheap, easy, effective, rugged and safe - with regard to other traditional methodologies.
\end{abstract}

Keywords: pesticides; milk; QuEChERS.

\section{INTRODUÇÃO}

O Brasil é um dos maiores países em relação à utilização de agrotóxicos. Em 2009, cerca de 720.000 t de produtos comerciais formulados foram vendidos, correspondendo a $330.000 \mathrm{t}$ de ingredientes ativos. ${ }^{1} \mathrm{O}$ estudo da classe dos organofosforados tem grande importância, devido ao seu uso intensivo e sua alta toxicidade. ${ }^{2}$

Os agrotóxicos são usados como a principal estratégia no combate e prevenção de pragas agrícolas e no aumento da produção de alimentos. Contudo, resíduos e traços desses princípios ativos e de seus produtos de degradação podem ficar nos alimentos e precisam ser monitorados para avaliação da ingesta do agente químico residual. ${ }^{3}$

$\mathrm{O}$ leite tem grande consumo nacional e pode conter resíduos de agrotóxicos provenientes de diferentes fontes, como contaminação de pastos, rações e cereais; contaminação do meio ambiente; uso de domissanitários nos currais e estabelecimentos de produção leiteira e, emprego de produtos veterinários no gado leiteiro. ${ }^{4}$

Neste trabalho foi avaliada a implementação de método analítico para determinação na matriz leite de resíduos de 49 agrotóxicos e 4 produtos de degradação da classe dos organofosforados. Dentre os organofosforados avaliados, $75 \%$ são permitidos para utilização na agricultura de cereais e hortifrutigranjeiros, aproximadamente $15 \%$ estão presentes em medicamentos veterinários e cerca de $20 \%$ possuem o seu uso permitido como domissanitário. ${ }^{5}$

Apesar de $15 \%$ dos organofosforados estudados não possuírem uso permitido no Brasil, foram incluídos na validação do método por necessidades nacionais de avaliação das boas práticas agrícolas. Os agrotóxicos clorfenvinfós, clorpirifós, diazinona, diclorvós, etiona e fenitrotiona são utilizados em medicamentos veterinários para o combate a ectoparasitas e, exceto o diclorvós, são também utilizados em hortifrutigranjeiros, cereais e domissanitários, representando quatro possíveis meios de deixarem seus resíduos no leite., ${ }^{4,6}$

A complexidade da composição dos alimentos acarreta dificuldades para a quantificação dos agrotóxicos, sendo necessária uma etapa de limpeza do extrato (clean up) para reduzir as interferências após

*e-mail: lucia.bastos@incqs.fiocruz.br a extração com solvente. Estas dificuldades foram minimizadas após o desenvolvimento de métodos multirresíduos, que possibilitaram a análise de um grande número de substâncias com altos percentuais de recuperação (exatidão) dos analitos e a remoção dos possíveis interferentes da amostra; apresentaram boa precisão e robustez e reduziram o trabalho técnico e o uso de solventes. ${ }^{7,8}$

Tendo em vista que a legislação brasileira permite o uso de mais de 200 ingredientes ativos, na agricultura e como domissanitários, a utilização de métodos multirresíduos é importante para agilizar o trabalho analítico e, assim, responder às demandas de saúde pública. ${ }^{3}$

Foi introduzido um novo método ${ }^{9}$ de preparo de amostra para extração de resíduos de agrotóxicos, que recebeu o nome fantasia de QuEChERS. Esse método busca refletir as suas maiores vantagens (Quick, Easy, Cheap, Effective, Rugged, Safe), isto é, rápido, fácil, econômico, efetivo, robusto e seguro. As etapas envolvidas no método são extração com acetonitrila seguida de partição, promovida pela adição de sais (sulfato de magnésio- $\mathrm{MgSO}_{4}$ ), cloreto de sódio $(\mathrm{NaCl})$ e/ou acetato de sódio $\left(\mathrm{Na}\left(\mathrm{C}_{2} \mathrm{H}_{3} \mathrm{O}_{2}\right)\right.$ e limpeza da amostra com sorventes, como $\mathrm{C}_{18}$, alumina, PSA (primary secondary amine) e carbono grafitado (para uso em amostras com clorofila).

A utilização do solvente acetonitrila permite a extração de uma ampla faixa de agrotóxicos com diferentes polaridades e, quando acidificada, favorece a extração de substâncias que apresentam problemas de estabilidade em meio básico. O uso da acetonitrila, contudo, não é adequado para análises em cromatografia a gás no modo splitless, devido a sua grande expansão de volume durante a vaporização, o que pode vir a interferir nos detectores seletivos e favorecer a degradação de alguns agrotóxicos. ${ }^{10}$ Em função disto, neste estudo, após o processo de extração com acetonitrila, na etapa final o extrato orgânico foi seco e o solvente substituído por acetato de etila, mais adequado à cromatografia a gás com detecção por fotometria de chama (CG-DFC).

A utilização do sal secante sulfato de magnésio tem como objetivo a remoção de água e o favorecimento da recuperação dos agrotóxicos polares. Em contrapartida, a hidratação do sulfato de magnésio gera uma reação exotérmica que aquece a amostra a temperaturas de 40 a $45{ }^{\circ} \mathrm{C}$ na etapa de extração/partição, favorecendo a recuperação dos agrotóxicos apolares. ${ }^{11}$ 
O método QuEChERS introduziu uma nova denominação ao procedimento de limpeza da amostra, chamada de extração em fase sólida dispersiva (D-SPE) no qual, diferentemente do procedimento de limpeza tradicional (SPE) que utiliza cartuchos ou colunas, os sorventes são adicionados diretamente ao extrato orgânico e permitem que a limpeza da amostra e a redução da água residual sejam realizadas concomitantemente ${ }^{9} \mathrm{O}$ método mostrou-se adequado também para amostras com baixos teores de gordura $(<2 \%$ de gordura) com o leite ${ }^{12}$ Ultra-alta temperatura (UAT).

O objetivo do trabalho foi a implementação de método de extração dispersiva QuEChERS em leite integral UAT em embalagem Tetra Pak e pasteurizado em embalagem plástica, para determinação de resíduos de agrotóxicos da classe dos organofosforados. Foram avaliados 49 agrotóxicos da classe dos organofosforados e 4 produtos de degradação, totalizando 53 substâncias.

\section{PARTE EXPERIMENTAL}

\section{Amostras branco do leite (matriz)}

Duas amostras de leite integral provenientes do estado de Minas Gerais - uma em embalagem Tetra Pak (UAT) e outra em embalagem plástica (leite pasteurizado tipo A) - foram analisadas na etapa de implementação do método. Como nos respectivos rótulos constava a informação de que ambas eram de procedência orgânica, foi feita uma análise prévia para confirmar a ausência dos agrotóxicos em estudo.

\section{Padrões e reagentes}

A maioria dos padrões de agrotóxicos certificados, da classe dos organofosforados, possuía grau de pureza superior a 95\% (Dr. Ehrenstorfer - Augsburg, Alemanha), exceto os agrotóxicos tiometona $(48 \%)$, profenofós $(92 \%)$, mevinfós $(91 \%)$, etoprofós $(93 \%)$, terbufós $(93 \%)$, etrinfos $(60 \%)$, fosfamidona $(92,5 \%)$, formotiona $(92 \%)$, fenamifós $(92,5 \%)$ e triazofós $(78 \%)$.

Foram utilizados acetonitrila, iso-octano e acetato de etila, solventes orgânicos de alta pureza e grau cromatográfico (Merck e Tedia); $\mathrm{MgSO}_{4} \mathrm{PA}$ (Merck); sorvente Bondesil-PSA $40 \mu \mathrm{m}$ (Varian); $\mathrm{C}_{18}$ 35-75 $\mu \mathrm{m}$ (Alltech); $\mathrm{Al}_{2} \mathrm{O}_{3}, 90$, neutro70-230 \# ASTM (Merck), previamente muflado a $550{ }^{\circ} \mathrm{C}$ por $3 \mathrm{~h} \mathrm{e} \mathrm{Na}\left(\mathrm{C}_{2} \mathrm{H}_{3} \mathrm{O}_{2}\right)$ anidro (Spectrum), seco a $220{ }^{\circ} \mathrm{C}$ por $3 \mathrm{~h}$ antes do uso.

\section{Soluções estoque}

Foram preparadas 53 soluções estoque (SE) dos agrotóxicos e/ ou derivados a serem avaliados em solvente acetato de etila na concentração nominal de $100 \mu \mathrm{g} \mathrm{mL} \mathrm{m}^{-1}$.

\section{Soluções intermediárias}

A partir das SE, foram preparadas duas soluções distintas (S1 e S2) intermediárias de trabalho. A escolha dos agrotóxicos de cada solução foi feita em função do tempo de retenção de cada substância, de modo que não houvesse duas com o mesmo tempo de retenção em $\min \left(t_{R} \min \right)$, possibilitando, dessa forma, uma separação inequívoca de todos os organofosforados avaliados. Quando na determinação analítica em uma amostra desconhecida ocorrer a presença de agrotóxicos com o mesmo $\mathrm{t}_{\mathrm{R}} \mathrm{min}$, a identidade do analito deverá ser confirmada pelo emprego de, pelo menos, um dos seguintes procedimentos: ${ }^{13}$ outra coluna com fase estacionária de polaridade diferente; outro detector ou espectrometria de massas com identificação pela biblioteca de espectros dos agrotóxicos.
A S1 foi composta dos seguintes agrotóxicos e de produtos de degradação, ordenados em ordem crescente de $t_{R}$ min entre parênteses: nalede $(3,694)$, metamidofós $(4,322)$, acefato $(7,287)$, demetom-S-metílico $(10,228)$, ometoato $(11,482)$, tiometona $(12,403)$, diazinona $(13,291)$, dissulfotom $(14,770)$, isazofós $(17,123)$, clorpirifós-metil $(19,805)$, parationa-metílica $(21,560)$, pirimifós-metílico $(22,053)$, paraoxon etílico $(22,440)$, fenitrotiona $(24,385)$, parationa-etílica $(24,945)$, bromofós-metílico $(29,762)$, bromofós-etílico $(29,762)$, protiofós $(33,690)$, profenofós $(37,002)$, dissulfotom-S-sulfurona $(40,815)$, etiona $(40,950)$, metidationa $(44,849)$, carbofenotiona $(48,435)$, fosalona $(66,500)$, pirazofós $(69,337)$ e azinfós-Etílico $(72,718)$. O paraoxon-etílico e a dissulfotom-S-sulfurona são produtos de degradação da parationa-etílica e dissulfotom, respectivamente.

A S2 foi composta dos seguintes agrotóxicos e de dois produtos de degradação, também ordenados em ordem crescente de $\mathrm{t}_{\mathrm{R}}$ min: diclorvós $(3,699)$, mevinfós $(5,710)$, etoprofós $(9,105)$, forato $(11,315)$, terbufós $(12,411)$, tebupirinfós $(12,571)$, monocrotofós $(14,589)$, etrinfos $(15,241)$, dimetoato $(16,403)$, paraoxon-metílico $(20,634)$, fosfamidona $(21,813)$, formotiona $(22,180)$, malaoxon $(23,509)$, clorpirifós $(24,646)$, malationa $(25,545)$, pirimifós-etílico $(27,276)$, fentiona $(27,803)$, clorfenvinfós $(30,705)$, tetraclorvinfós $(35,711)$, iodofenfós $(37,429)$, fenamifós $(38,004)$, vamidotiona $(41,968)$, sulprofós $(47,676)$, triazofós $(55,106)$, piridafentiona $(63,645)$, fosmete $(66,536)$, azinfós-metílico $(71,084)$. O paraoxon-metílico e o malaoxon são produtos de degradação da parationa-metílica e malationa, respectivamente.

As Figuras 1 e 2 apresentam os cromatogramas das S1 e S2 dos agrotóxicos estudados na matriz leite.

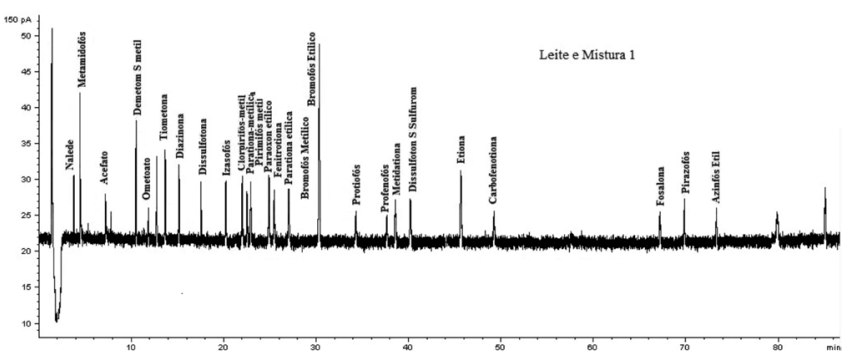

Figura 1. Cromatograma com os organofosforados estudados na S1 em matriz leite na concentração nominal de 0,01 $\mu \mathrm{g} \mathrm{mL}^{-1}$

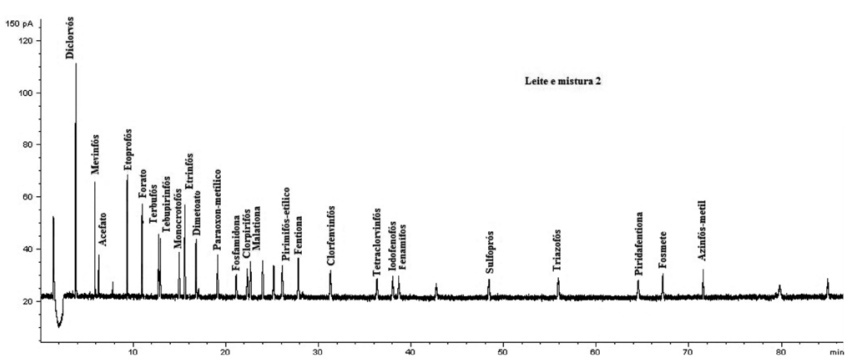

Figura 2. Cromatograma com os organofosforados estudados na $\mathrm{S} 2$ em matriz leite na concentração nominal de 0,01 $\mu \mathrm{g} \mathrm{mL}^{-1}$

As $\mathrm{S} 1$ e S2 foram utilizadas para preparo das curvas analíticas em acetato de etila, no extrato de leite orgânico branco e na fortificação do leite branco no estudo da taxa de recuperação.

\section{Soluções intermediárias utilizadas na qualidade assegurada}

Para garantir o controle individual do processo analítico e a validade dos resultados, foram utilizadas duas soluções intermediárias (QA1 e QA2): clorpirifós-metil, na concentração nominal de $0,3 \mu \mathrm{g} \mathrm{mL} \mathrm{m}^{-1} \mathrm{em}$ solvente acetato de etila (QA1), foi escolhido por 
representar adequadamente as características físicas e químicas da classe dos organofosforados ${ }^{14}$

Os resultados analíticos da amostra são considerados válidos se a recuperação do clorpirifós-metil estiver entre 70 e $120 \%$. Caso contrário, deve-se verificar todo o procedimento realizado e, se necessário, repetir o processo de extração e limpeza da amostra. ${ }^{13}$

Para o controle do equipamento, a parationa-metílica, na concentração nominal de $1 \mu \mathrm{g} \mathrm{mL}^{-1} \mathrm{em}$ acetato de etila (QA2), foi inserida no início de cada sequência de injeção, com o objetivo de monitorar o sistema cromatográfico no momento da análise das amostras.

$\mathrm{O}$ critério de avaliação adotado foi o $\mathrm{CV}$ de $10 \%$ para a área obtida no QA2. Contudo, um novo CV poderá ser determinado com base em uma série histórica de sucessivas avaliações.

\section{Condições cromatográficas}

Equipamento: cromatógrafo a gás HP 7890 (Agilent), equipado com detector por fotometria de chama (CG-DFC) em modo fósforo $(\mathrm{P})$; sistema de injeção automático e estação de trabalho - ChemStation. Temperaturas do injetor e detector de 230 e $250{ }^{\circ} \mathrm{C}$, respectivamente. Coluna $50 \%$ fenil-metil siloxano (DB-17MS) com $30 \mathrm{~m}$ de comprimento; $0,25 \mathrm{~mm}$ de d.i. e $0,25 \mu \mathrm{m}$ de espessura de filme. Programação de temperatura do forno de $100{ }^{\circ} \mathrm{C}(0 \mathrm{~min})$, $25^{\circ} \mathrm{C} / \mathrm{min}$ a $170{ }^{\circ} \mathrm{C}(1 \mathrm{~min}), 1^{\circ} \mathrm{C} / \mathrm{min}$ a $180^{\circ} \mathrm{C}(1 \mathrm{~min}), 1^{\circ} \mathrm{C} / \mathrm{min}$ até $230{ }^{\circ} \mathrm{C}(0 \mathrm{~min}), 5^{\circ} \mathrm{C} / \mathrm{min}$ até $260^{\circ} \mathrm{C}(5 \mathrm{~min}), 20^{\circ} \mathrm{C} / \mathrm{min}$ até $280{ }^{\circ} \mathrm{C}$ (10 min). Fluxo de gás carreador (hélio) $=1,5 \mathrm{~mL} \mathrm{~min}^{-1}$, fluxo da purga do septo $=3,0 \mathrm{~mL} \mathrm{~min}^{-1}$, fluxo total $=61,5 \mathrm{~mL} \mathrm{~min}^{-1}$, fluxo do gás make-up (nitrogênio) $=60 \mathrm{~mL} \mathrm{~min}^{-1}$, modo de injeção splitless $=$ $1,0 \mathrm{~min}$, volume injetado $=1,0 \mu \mathrm{L}$.

O tempo total de corrida foi de 80 min e a integração foi feita pelo parâmetro da área dos picos.

\section{Procedimento analítico multirresíduos}

O método multirresíduos utilizado foi baseado em metodologia ${ }^{9}$ desenvolvida em 2003 denominada QuEChERS.

\section{Extração dos agrotóxicos}

Cerca de $15 \mathrm{~g}$ da amostra, após homogeneização por $5 \mathrm{~min}$ em liquidificador de copo de vidro, foram pesadas e colocadas em frasco de $50 \mathrm{~mL}$ para uso em centrífuga. Em seguida, foi adicionado $1 \mathrm{~mL}$ do QA1 (clorpirifós-metil) e homogeneizado. Após $25 \mathrm{~min}$, foi iniciada a extração, com a adição de $15 \mathrm{~mL}$ de acetonitrila (1\% ácido acético) e agitação em vortex. Foram realizadas duas etapas de limpeza da amostra com extração em fase sólida dispersiva (SPE-D): na primeira, foram adicionados $\mathrm{MgSO}_{4}+1,5 \mathrm{~g} \mathrm{Na}\left(\mathrm{C}_{2} \mathrm{H}_{3} \mathrm{O}_{2}\right)$ e na segunda, foram estudadas várias combinações de sorventes, listados abaixo. O diagrama das duas etapas de extração dispersiva encontra-se apresentado na Figura 3.

\section{Critérios utilizados na avaliação do método}

O primeiro critério a ser avaliado foi o da seletividade, após este se avaliou a melhor combinação de sorventes em fase estacionária para a segunda etapa da SPE-D, o efeito matriz, linearidade, precisão, exatidão, limites de detecção e quantificação.

\section{Seletividade}

As amostras branco matriz de leite foram submetidas ao método de extração de organofosforados e a seletividade foi confirmada pela ausência de picos nos tempos de retenção das substâncias estudadas presentes nas $\mathrm{S} 1$ e S2. ${ }^{14}$

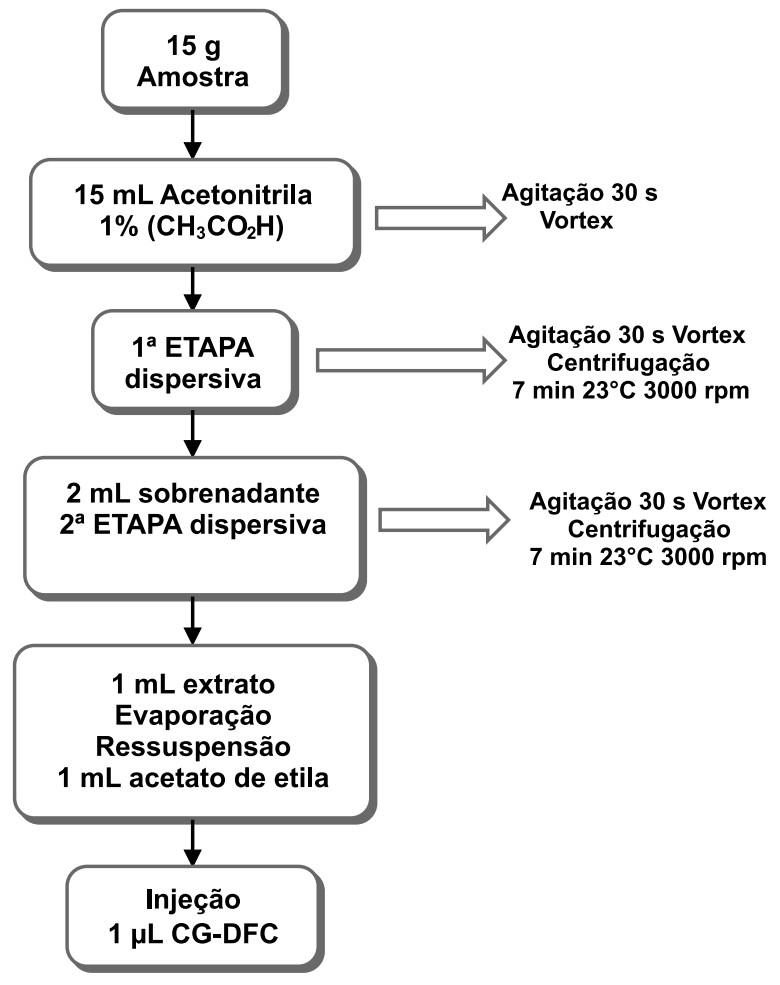

Figura 3. Diagrama do método QuEChERS empregado na validação de resíduos de organofosforados na matriz leite

Avaliação da melhor combinação de sorventes para extração em fase sólida dispersiva (SPE-D)

As amostras branco foram fortificadas, respectivamente, com concentrações que variaram de 0,050 a $0,100 \mathrm{mg} \mathrm{kg}^{-1}$ das S1 e S2, de acordo com os organofosforados estudados. Após $25 \mathrm{~min} \mathrm{da}$ fortificação, que permitiu a interação entre o agrotóxico e a matriz, iniciou-se o processo de extração. Foram utilizadas seis diferentes combinações de sorventes para avaliação da melhor taxa de recuperação dos organofosforados adicionados na S1 e S2: A) $50 \mathrm{mg}$ PSA + $150 \mathrm{mg} \mathrm{MgSO}_{4}$; B) $50 \mathrm{mg} \mathrm{C}_{18}+150 \mathrm{mg} \mathrm{MgSO}_{4}$; C) $50 \mathrm{mg}$ alumina + $150 \mathrm{mg} \mathrm{MgSO}_{4}$; D) $50 \mathrm{mg} \mathrm{PSA}+50 \mathrm{mg} \mathrm{C}_{18}+150 \mathrm{mg}$ $\mathrm{MgSO}_{4}$; E) $50 \mathrm{mg} \mathrm{PSA}+50 \mathrm{mg}$ alumina $+150 \mathrm{mg} \mathrm{MgSO}{ }_{4}$ e F) $50 \mathrm{mg}$ $\mathrm{PSA}+50 \mathrm{mg} \mathrm{C}_{18}+50 \mathrm{mg}$ alumina $+150 \mathrm{mg} \mathrm{\textrm {MSO } _ { 4 }}$.

Em seguida, as recuperações dos 53 analitos presentes na S1 e S2 foram avaliadas e comparadas com a concentração real das amostras fortificadas (leite com S1 ou S2).

Efeito da resposta cromatográfica acentuada e induzida pela matriz branco do leite

A natureza da matriz ("efeito matriz") - solventes orgânicos ${ }^{15}$ ou extrato da amostra - que contém os analitos pode aumentar ou diminuir a resposta do detector.

Para se avaliar este efeito, seguiu-se o procedimento ${ }^{16}$ que identificou a resposta cromatográfica de cada organofosforado em solvente e na matriz tomate. Utilizou-se a matriz leite integral UAT e foram analisadas as soluções $\mathrm{S} 1$ e S2 em cinco diferentes níveis, correspondentes às concentrações nominais de 0,$01 ; 0,02 ; 0,03 ; 0,04 \mathrm{e} 0,05 \mu \mathrm{g} \mathrm{mL} \mathrm{mL}^{-1}$.

\section{Estudo da linearidade da faixa de trabalho}

Para o estudo da linearidade da faixa de trabalho, $1 \mathrm{~mL}$ do extrato 
orgânico do branco de leite, colocado em frascos de vidro de $3 \mathrm{~mL}$, foi seco sob a atmosfera de $\mathrm{N}_{2}$. Em seguida, adicionou-se $1 \mathrm{~mL}$ dos extratos orgânicos $\mathrm{S} 1$ e S2, respectivamente, nas concentrações correspondentes aos pontos da curva analítica $\left(0,01\right.$ a $\left.0,05 \mu \mathrm{g} \mathrm{mL}^{-1}\right)$.

$\mathrm{O}$ volume de $1 \mu \mathrm{L}$ de cada concentração foi injetado em triplicata no sistema CG-DFC e, para os cálculos estatísticos, utilizou-se o valor médio dos resultados obtidos.

A linearidade da faixa de trabalho foi verificada através da leitura da curva analítica, utilizando o método dos mínimos quadrados ordinários (MMQO). ${ }^{16}$

\section{Limites de detecção e de quantificação do instrumento e do método}

Os limites de detecção e quantificação do instrumento (LDI e LQI) e do método (LDM e LQM) foram estabelecidos com base no método da relação sinal/ruído (S/R), no qual se aceita a estimativa de 3:1 para o LD e de 10:1 para o LQ, ou seja, o ruído produzido pela resposta da injeção de concentrações conhecidas dos analitos de interesse deve ser três vezes maior do que o ruído produzido pelo sistema cromatográfico da linha de base para o LD e dez vezes para o LQ. ${ }^{16}$ Esta relação (S/R) foi calculada pela ChemStation do cromatógrafo HP-7890.

Para estabelecer esta relação para os valores dos LDI e LQI utilizou-se uma concentração conhecida com aproximadamente $0,01 \mu \mathrm{g} \mathrm{mL}^{-1}$ de todos os agrotóxicos em matriz (extrato branco da polpa de leite em acetato de etila), analisados em três replicatas genuínas $(n=3)$.

Para o cálculo de LDM e LQM, seis replicatas genuínas da amostra branco de leite foram fortificadas com a concentração de aproximadamente $0,01 \mu \mathrm{g} \mathrm{mL}^{-1} \mathrm{e}$ analisadas pelo método de ensaio. Os resultados obtidos foram utilizados para estabelecer a relação (S/R). Em seguida, calcularam-se as médias, os desvios padrão dos resultados e os valores dos limites LDI, LQI, LDM e LQM.

Para confirmação dos resultados dos analitos foram preparadas seis replicatas da amostra branco do leite nas concentrações obtidas dos LQM, calculados de cada analito analisado de acordo com o método de ensaio. No caso dos analitos cujos valores $S / R$ não foram iguais ou superiores a 3:1, as concentrações individuais foram aumentadas, o que permitiu a obtenção de valores mais próximos do LDM e LQM.

\section{Recuperação e repetitividade}

O mesmo procedimento utilizado para cálculo do LDM e do LQM foi usado para o cálculo da taxa de recuperação e repetitividade dos 53 analitos e os critérios de aceitação foram os indicados pelo Codex Alimentarius ${ }^{17} \mathrm{e} \mathrm{SANCO}^{13}$ : para a faixa de concentração deste estudo ( $\left.>0,01 \mathrm{e} \leq 0,1 \mathrm{mg} \mathrm{kg}^{-1}\right)$, o intervalo de recuperação deve ser de 70 a $120 \%$ e os coeficientes de variação (CV) devem ser inferiores a $20 \%$.

\section{RESULTADOS E DISCUSSÃO}

\section{Seletividade}

As duas amostras branco de leite utilizadas como matriz foram adequadas para a avaliação do método, por não terem apresentado $t_{R}$ min iguais aos dos agrotóxicos em estudo.

\section{Avaliação da melhor combinação de sorventes para utilização na segunda fase dispersiva}

Dentre as seis combinações de sorventes testadas, apenas as com $50 \mathrm{mg} \mathrm{PSA}+50 \mathrm{mg}$ alumina $+150 \mathrm{mg} \mathrm{MgSO}_{4}$ e com $50 \mathrm{mg}$

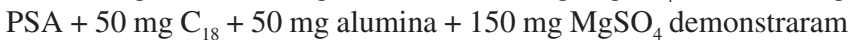

maior uniformidade nas recuperações para o conjunto de agrotóxicos avaliados nas misturas $\mathrm{S} 1$ e S2, considerando a faixa estipulada pelo $\operatorname{SANCO}^{13}$ (70 a 120\%). A combinação $50 \mathrm{mg}$ PSA + $50 \mathrm{mg}$ alumina $+150 \mathrm{mg} \mathrm{MgSO}_{4}$ foi a escolhida, para ser utilizada na segunda fase dispersiva, por apresentar um desempenho melhor para os organofosforados acefato e clorfenvinfós ( 99 e $81 \%$, respectivamente), quando comparada à com $50 \mathrm{mg} \mathrm{PSA}+50 \mathrm{mg} \mathrm{C}_{18}+50 \mathrm{mg}$ alumina $+150 \mathrm{mg}$ $\mathrm{MgSO}_{4}(65$ e $63 \%)$, e por utilizar uma fase dispersiva a menos $\left(\mathrm{C}_{18}\right)$.

Em trabalho anterior, ${ }^{12}$ o método Quechers em leite (tipo de leite não especificado) foi avaliado por CG-MS para diferentes agrotóxicos, dentre esses o acefato. Foi obtida uma recuperação para o agrotóxico estudado de $107 \%(\mathrm{n}=3)$, na concentração de $0,05 \mathrm{mg} \mathrm{kg}^{-1}$, utilizando a fase dispersiva $50 \mathrm{mg}$ PSA $+50 \mathrm{mg} \mathrm{C} 18+150 \mathrm{mg} \mathrm{MgSO}$. Neste estudo somente foi avaliada essa combinação, não tendo sido também avaliado o agrotóxico clorfenvinfós.

Para os agrotóxicos estudados (S1 e S2), as concentrações utilizadas para fortificar a matriz e os resultados das recuperações obtidas com as seis diferentes combinações de sorventes estão descritas na Tabela $2 \mathrm{~S}$, material suplementar, na qual é possível verificar as melhores taxas de recuperação (70 a 120\%) em um maior número de agrotóxicos avaliados. O agrotóxico diclorvós - também denominado DDVP - não apresentou recuperação adequada com nenhuma das combinações estudadas, o que pode estar relacionado a vários fatores, como a integridade do material de referência utilizado ou à extração da molécula.

Trabalho de monitoramento realizado na Espanha ${ }^{2}$ mostrou a presença de resíduos de diclorvós em 5,78\% das amostras avaliadas de leite cru.

Como o DDVP está presente em 39 medicamentos veterinários antiparasitários e é também um produto de degradação de 21 produtos cujo ingrediente ativo é o triclorfom (não avaliado neste método), ambos utilizados no gado leiteiro, conforme registros no MAPA ${ }^{18}$ novos estudos deverão ser feitos para adequar um método para análise deste organofosforado.

\section{Efeito da resposta cromatográfica acentuada e induzida pela matriz branco do leite}

Em 30\% de todos os agrotóxicos analisados - acefato, azinfós-etílico, demetom-S-metílico, dimetoato, fenamifós, formotiona fosfamidona, fosmete, malaoxon, metamidofós, ometoato, paraoxon-metílico, profenofós, monocrotofós, piridafentiona, tetraclorvinfós, triazofós e vamidotiona - o efeito matriz foi significante nos cinco níveis testados.

Em 12\% - azinfós-metilico, etoprofós, nalede, protiofós, fentiona, pirimifós-etílico, terbufós - não foi demonstrado efeito matriz em nenhum dos níveis avaliados $\left(0,01 ; 0,02 ; 0,03 ; 0,04\right.$ e $\left.0,05 \mu \mathrm{g} \mathrm{mL}^{-1}\right)$. Nos $58 \%$ restantes, correspondentes a 28 agrotóxicos, o efeito matriz foi observado em pelo menos um nível. O detalhamento da presença do efeito matriz em diferentes níveis encontra-se representado na Tabela 1S, material suplementar.

Tendo em vista que o efeito matriz branco do leite foi significante para a maioria dos organofosforados testados, utilizou-se curva com matriz para determinar a linearidade e faixa de trabalho.

\section{Estudo da linearidade e faixa de trabalho}

A correlação da curva analítica, representada pelo modelo matemático entre os valores numéricos de $x$ e de $y$, é indicada pelo coeficiente de Pearson - ' $r$ '. O quadrado deste coeficiente é chamado de coeficiente de determinação ou simplesmente $\mathrm{R}^{2}$. Os valores aceitos foram $\mathrm{R}^{2} \geq 0,95$ e $\mathrm{r} \geq 0,98$.

Em 40 dos 53 organofosforados avaliados foi possível observar que a regressão foi significativa e não demonstrou desvio da linearidade na faixa avaliada $\left(0,01\right.$ a $\left.0,05 \mu \mathrm{g} \mathrm{mL} \mathrm{m}^{-1}\right)$. 
Tabela 1. Limites de detecção (LDM) e de quantificação do método (LQM), calculados a partir da razão sinal/ruído, para os agrotóxicos referentes a S1

\begin{tabular}{|c|c|c|c|c|c|c|}
\hline \multirow[t]{2}{*}{ Agrotóxico } & \multirow{2}{*}{$\begin{array}{c}\text { Conc. } \\
\left(\mu \mathrm{g} \mathrm{mL}^{-1}\right)\end{array}$} & \multirow{2}{*}{$\begin{array}{c}\text { Relação } \\
\text { sinal/ruído }\end{array}$} & \multirow[t]{2}{*}{ Áreas } & \multirow{2}{*}{$\begin{array}{c}\text { Desvio padrão } \\
\text { áreas }\end{array}$} & \multicolumn{2}{|c|}{$\begin{array}{l}\text { Limites do método } \\
\left(\mu g \mathrm{~g}^{-1}\right)\left(\mathrm{mg} \mathrm{kg}^{-1}\right)\end{array}$} \\
\hline & & & & & LDM & LQM \\
\hline Acefato & 0,015 & 3,8 & 36,44 & 11 & 0,014 & 0,051 \\
\hline Azinfós-etílico & 0,014 & 3,3 & 44,49 & 4 & 0,004 & 0,012 \\
\hline Bromofós-etílico & 0,052 & 11,4 & 189,43 & 10 & 0,008 & 0,030 \\
\hline Bromofós-metílico & 0,014 & 3,2 & 46,98 & 3 & 0,003 & 0,010 \\
\hline Carbofenotiona & 0,070 & 9,9 & 210,07 & 1 & 0,010 & 0,033 \\
\hline Clorpirifós-metil & 0,012 & 3,9 & 51,07 & 2 & 0,001 & 0,005 \\
\hline Demetom-S-metil & 0,011 & 6,8 & 50,68 & 2 & 0,001 & 0,005 \\
\hline Diazinona & 0,014 & 6,6 & 62,17 & 3 & 0,002 & 0,003 \\
\hline Dissulfotona & 0,011 & 4,8 & 50,56 & 3 & 0,002 & 0,006 \\
\hline Dissulfotona-S-sulfurona & 0,021 & 3,5 & 67,08 & 3 & 0,003 & 0,009 \\
\hline Etiona & 0,015 & 4,1 & 77,38 & 1 & 0,003 & 0,011 \\
\hline Fenitrotiona & 0,011 & 4,0 & 58,66 & 2 & 0,001 & 0,004 \\
\hline Fosalona & 0,067 & 12,2 & 204.32 & 6 & 0,006 & 0,020 \\
\hline Izasofós & 0,010 & 3,7 & 45,38 & 2 & 0,001 & 0,004 \\
\hline Metidationa & 0,017 & 3,2 & 59,12 & 3 & 0,007 & 0,010 \\
\hline Metamidofós & 0,014 & 10,9 & 69,76 & 3 & 0,002 & 0,006 \\
\hline Nalede & 0,010 & 4,9 & 16,94 & 1 & 0,002 & 0,007 \\
\hline Ometoato & 0,075 & 11,4 & 105,32 & 9 & 0,019 & 0,069 \\
\hline Paraoxon-etílico & 0,012 & 3,6 & 49,61 & 1 & 0,001 & 0,004 \\
\hline Parationa-etíllica & 0,010 & 3,1 & 43,92 & 1 & 0,001 & 0,002 \\
\hline Parationa-metílica & 0,010 & 4,2 & 55,44 & 2 & 0,001 & 0,006 \\
\hline Pirazofós & 0,014 & 3,6 & 44,25 & 3 & 0,003 & 0,011 \\
\hline Pirimifós-metílico & 0,011 & 3,4 & 47,77 & 4 & 0,002 & 0,006 \\
\hline Profenofós & 0,077 & 9,3 & 179,59 & 10 & 0,013 & 0,030 \\
\hline Protiofós & 0,066 & 10,2 & 190,05 & 13 & 0,014 & 0,048 \\
\hline Tiometona & 0,010 & 5,5 & 47,16 & 3 & 0,020 & 0,080 \\
\hline
\end{tabular}

Tabela 2. Limites de detecção (LDM) e de quantificação do método (LQM), calculados a partir da razão sinal/ruído, para os agrotóxicos referentes a S2

\begin{tabular}{|c|c|c|c|c|c|c|}
\hline \multirow[t]{2}{*}{ Agrotóxico } & \multirow{2}{*}{$\begin{array}{c}\text { Conc. } \\
\left(\mu \mathrm{g} \mathrm{mL}^{-1}\right)\end{array}$} & \multirow{2}{*}{$\begin{array}{c}\text { Relação } \\
\text { sinal/ruído }\end{array}$} & \multirow[t]{2}{*}{ Áreas } & \multirow{2}{*}{$\begin{array}{l}\text { Desvio padrão } \\
\text { áreas }\end{array}$} & \multicolumn{2}{|c|}{$\begin{array}{l}\text { Limites do método } \\
\left(\mu \mathrm{g} \mathrm{g}^{-1}\right)\left(\mathrm{mg} \mathrm{kg}^{-1}\right)\end{array}$} \\
\hline & & & & & LDM & LQM \\
\hline Azinfós-metílico & 0,011 & 3,0 & 28,56 & 2 & 0,008 & 0,010 \\
\hline Clorfenvinfós & 0,100 & 13,1 & 233,13 & 13 & 0,016 & 0,053 \\
\hline Clorpirifós & 0,010 & 3,9 & 56,27 & 2 & 0,001 & 0,003 \\
\hline Diclorvós & 0,015 & 22,8 & 74,19 & 1 & 0,001 & 0,002 \\
\hline Dimetoato & 0,010 & 5,0 & 57,29 & 3 & 0,002 & 0,006 \\
\hline Etoprofós & 0,052 & 10,4 & 71,91 & 2 & 0,001 & 0,004 \\
\hline Etrinfós & 0,011 & 7,7 & 84,55 & 2 & 0,001 & 0,003 \\
\hline Fenamifós & 0,060 & 9,4 & 199,21 & 13 & 0,012 & 0,040 \\
\hline Fentiona & 0,011 & 3,6 & 57,01 & 3 & 0,002 & 0,006 \\
\hline Forato & 0,013 & 8,0 & 62,92 & 1 & 0,001 & 0,003 \\
\hline Formotiona & 0,010 & 3,4 & 47,50 & 2 & 0,001 & 0,004 \\
\hline Fosmete & 0,071 & 11,0 & 189,31 & 9 & 0,011 & 0,037 \\
\hline Fosfamidom & 0,072 & 10,9 & 157,58 & 3 & 0,004 & 0,013 \\
\hline Iodofenfós & 0,663 & 8,2 & 162.17 & 10 & 0,129 & 0,430 \\
\hline Malaoxon & 0,020 & 3,02 & 38,13 & 3 & 0,005 & 0,017 \\
\hline Malationa & 0,011 & 3,1 & 46,74 & 2 & 0,002 & 0,006 \\
\hline Mevinfós & 0,012 & 9,5 & 41,78 & 2 & 0,001 & 0,005 \\
\hline Terbufós & 0,012 & 6,0 & 55,69 & 4 & 0,002 & 0,008 \\
\hline Tebupirifós & 0,011 & 5,0 & 46,26 & 2 & 0,002 & 0,005 \\
\hline Monocrotofós & 0,013 & 3,6 & 39,77 & 4 & 0,004 & 0,006 \\
\hline Paraoxon-metílico & 0,010 & 3,8 & 47,39 & 2 & 0,002 & 0,006 \\
\hline Piridafentiona & 0,072 & 9,6 & 217,95 & 11 & 0,011 & 0,040 \\
\hline Pirimifós-etílico & 0,010 & 3,0 & 47,25 & 4 & 0,003 & 0,008 \\
\hline Sulprofós & 0,069 & 9,7 & 208,16 & 11 & 0,011 & 0,039 \\
\hline Tetraclorvinfós & 0,068 & 8,8 & 172,06 & 9 & 0,010 & 0,072 \\
\hline Triazofós & 0,066 & 10,8 & 234,27 & 11 & 0,009 & 0,029 \\
\hline Vamidotiona & 0,087 & 4,7 & 99,19 & 5 & 0,013 & 0,042 \\
\hline
\end{tabular}


Tabela 3. Valores de recuperação (\%), desvio padrão e coeficiente de variação (CV, \%) calculados para as seis replicatas genuínas (representadas de 1 a 6$)$ na concentração (conc.) variando de 0,01 a $0,10 \mathrm{mg} \mathrm{kg}^{-1}$, para as S1 e S2

\begin{tabular}{|c|c|c|c|c|c|c|c|c|c|c|}
\hline Agrotóxico & $\begin{array}{c}\text { Conc. } \\
\left(\mathrm{mg} \mathrm{kg}^{-1}\right)\end{array}$ & 1 & 2 & 3 & 4 & 5 & 6 & Média & $\begin{array}{l}\text { Desvio } \\
\text { padrão }\end{array}$ & $\mathrm{CV} \%$ \\
\hline Acefato & 0,070 & 108 & 98 & 107 & 94 & 110 & 134 & 109 & 13 & 12 \\
\hline Azinfós-etílico & 0,070 & 98 & 108 & 110 & 101 & 98 & 102 & 103 & 5 & 5 \\
\hline Bromofós-etílico & 0,070 & 97 & 96 & 94 & 91 & 91 & 94 & 94 & 2 & 2 \\
\hline Bromofós-metílico & 0,018 & 98 & 108 & 110 & 101 & 98 & 102 & 103 & 5 & 5 \\
\hline Carbofenotiona & 0,070 & 101 & 99 & 103 & 101 & 99 & 113 & 103 & 5 & 5 \\
\hline Clorfenvinfós & 0,100 & 107 & 111 & 110 & 101 & 104 & 115 & 108 & 5 & 4 \\
\hline Clorpirifós & 0,014 & 90 & 77 & 78 & 86 & 78 & 83 & 82 & 5 & 6 \\
\hline Clorpirifós-metílico & 0,016 & 104 & 101 & 106 & 101 & 106 & 110 & 105 & 3 & 3 \\
\hline Demeton-S-metílico & 0,014 & 107 & 97 & 103 & 94 & 93 & 95 & 98 & 5 & 5 \\
\hline Diazinona & 0,019 & 99 & 98 & 97 & 95 & 95 & 97 & 97 & 1 & 2 \\
\hline Diclorvós* & 0,019 & 48 & 47 & 47 & 46 & 41 & 46 & 46 & 2 & 5 \\
\hline Diclorvós* & 0,097 & 42 & 42 & 46 & 56 & 43 & 59 & 48 & 7 & 14 \\
\hline Dimetoato & 0,014 & 112 & 103 & 95 & 100 & 97 & 93 & 100 & 6 & 6 \\
\hline Dissulfotona & 0,014 & 90 & 91 & 91 & 89 & 90 & 89 & 90 & 1 & 1 \\
\hline Dissulfoton-S-Sulforom & 0,100 & 104 & 103 & 115 & 109 & 104 & 123 & 110 & 7 & 7 \\
\hline Etiona & 0,020 & 95 & 95 & 93 & 86 & 93 & 92 & 92 & 3 & 3 \\
\hline Etoprofós & 0,018 & 104 & 87 & 94 & 93 & 93 & 89 & 93 & 5 & 6 \\
\hline Etrinfos & 0,014 & 105 & 94 & 92 & 95 & 94 & 90 & 95 & 5 & 5 \\
\hline Fenamifós & 0,100 & 106 & 122 & 115 & 105 & 115 & 127 & 115 & 8 & 7 \\
\hline Fenitrotiona & 0,015 & 104 & 100 & 100 & 100 & 104 & 101 & 102 & 2 & 2 \\
\hline Fentiona & 0,015 & 100 & 84 & 87 & 81 & 91 & 84 & 88 & 6 & 7 \\
\hline Formotiona & 0,013 & 78 & 66 & 79 & 73 & 69 & 66 & 72 & 5 & 7 \\
\hline Forato & 0,018 & 95 & 85 & 81 & 79 & 78 & 76 & 82 & 6 & 8 \\
\hline Fosalona & 0,010 & 88 & 92 & 86 & 79 & 77 & 79 & 84 & 6 & 7 \\
\hline Fosfamidom & 0,060 & 108 & 111 & 111 & 100 & 104 & 111 & 108 & 4 & 4 \\
\hline Iodofenfós & 0,070 & 99 & 103 & 97 & 92 & 87 & 94 & 95 & 5 & 5 \\
\hline Izasofós & 0,013 & 112 & 106 & 109 & 103 & 109 & 106 & 108 & 3 & 3 \\
\hline Malaoxon & 0,020 & 96 & 95 & 88 & 89 & 94 & 99 & 94 & 3 & 9 \\
\hline Malationa & 0,015 & 109 & 89 & 91 & 98 & 96 & 83 & 94 & 8 & 9 \\
\hline Metamidofós & 0,018 & 83 & 80 & 97 & 80 & 85 & 88 & 86 & 6 & 7 \\
\hline Metidationa & 0,080 & 108 & 100 & 114 & 106 & 107 & 122 & 110 & 7 & 6 \\
\hline Mevinfós & 0,016 & 98 & 83 & 84 & 87 & 81 & 78 & 85 & 6 & 7 \\
\hline Monocrotofós & 0,018 & 102 & 98 & 100 & 91 & 87 & 86 & 94 & 6 & 7 \\
\hline Nalede & 0,013 & 86 & 81 & 89 & 79 & 69 & 70 & 79 & 7 & 9 \\
\hline Ometoato & 0,070 & 107 & 101 & 104 & 102 & 111 & 132 & 110 & 11 & 10 \\
\hline Paraoxon-etil & 0,015 & 121 & 108 & 108 & 98 & 110 & 106 & 109 & 7 & 6 \\
\hline Paraoxon-metil & 0,016 & 94 & 95 & 87 & 90 & 86 & 92 & 91 & 3 & 4 \\
\hline Parationa-etílica & 0,014 & 102 & 85 & 96 & 88 & 85 & 88 & 91 & 6 & 7 \\
\hline Parationa-metílica & 0,013 & 111 & 104 & 103 & 101 & 96 & 108 & 104 & 5 & 5 \\
\hline Pirazofós & 0,070 & 97 & 100 & 108 & 104 & 104 & 119 & 105 & 7 & 7 \\
\hline Piridafentiona & 0,070 & 107 & 118 & 116 & 104 & 111 & 119 & 113 & 6 & 5 \\
\hline Pirimifós-etílico & 0,070 & 99 & 104 & 98 & 91 & 98 & 106 & 99 & 5 & 5 \\
\hline Pirimifós-metílico & 0,010 & 111 & 99 & 102 & 95 & 97 & 97 & 100 & 5 & 5 \\
\hline Protiofós & 0,060 & 93 & 89 & 98 & 97 & 94 & 104 & 96 & 5 & 5 \\
\hline Profenofós & 0,070 & 92 & 103 & 115 & 108 & 104 & 117 & 107 & 8 & 8 \\
\hline Sulprofós & 0,070 & 95 & 106 & 99 & 97 & 93 & 99 & 98 & 4 & 4 \\
\hline Terbufós & 0,016 & 98 & 83 & 82 & 84 & 84 & 81 & 85 & 6 & 7 \\
\hline Tebupirinfós & 0,015 & 99 & 78 & 80 & 83 & 80 & 83 & 84 & 7 & 8 \\
\hline Tetraclorvinfós & 0,070 & 107 & 113 & 111 & 96 & 104 & 105 & 106 & 5 & 5 \\
\hline Tiometona & 0,013 & 94 & 92 & 100 & 91 & 94 & 95 & 94 & 3 & 3 \\
\hline Triazofós & 0,070 & 109 & 120 & 111 & 99 & 105 & 118 & 110 & 7 & 7 \\
\hline Vamidotiona & 0,070 & 111 & 126 & 115 & 111 & 121 & 121 & 118 & 6 & 5 \\
\hline
\end{tabular}

*Recuperações fora da faixa do SANCO. 
Para os agrotóxicos diclorvós, etrinfos, forato, mevinfós, nalede e terbufós a faixa de ajuste linear somente foi obtida para um intervalo menor $\left(0,02 \mathrm{a} 0,05 \mu \mathrm{g} \mathrm{mL} \mathrm{m}^{-1}\right)$, pois esses agrotóxicos não apresentaram uma boa sensibilidade no primeiro ponto da curva $\left(0,01 \mu \mathrm{g} \mathrm{mL}^{-1}\right)$.

$\mathrm{Na}$ Tabela 3S, material suplementar, estão representadas as equações da reta de regressão empregada para verificação da significância da regressão, do desvio da linearidade e da avaliação da homogeneidade da variância dos resíduos da regressão da curva analítica da matriz branco do leite, para os 49 agrotóxicos estudados e os 4 produtos de degradação. Na mesma tabela também consta o teste estatístico utilizado para avaliar a variância dos resíduos provenientes do ajuste da curva analítica e está demonstrado que todos os agrotóxicos testados apresentaram comportamento homoscedástico (Ccalculado < Ctabelado).

Todos os agrotóxicos avaliados apresentaram o valor de $\mathrm{R}^{2}$ dentro da faixa aceitável $\left(R^{2} \geq 0,95\right.$ e $\left.r \geq 0,98\right)$.

\section{Limites de detecção e de quantificação do método}

Os valores de LDM e LQM, obtidos por S/R, encontram-se nas Tabelas 1 e 2. Os agrotóxicos de S1 (acefato, azinfós-etílico, carbofenotiona, dissulfotom-S-sulfurom, fosalona, metidationa, ometoato, pirazofós, profenofós e protiofós) e os de $\mathrm{S} 2$ (fosfamidona, malaoxon, pirimifós-etílico, clorfenvinfós, tetraclorvinfós, iodofenfós, fenamifós, vamidotiona, sulprofós, triazofós, piridafentiona, fosmete, sulprofós, triazofós, piridafentiona e fosmete) não apresentaram S/R na proporção $3: 1$ na concentração de $0,01 \mathrm{mg} \mathrm{kg}^{-1}$. Por esta razão, aumentou-se a concentração desses agrotóxicos, de modo a se obter $\mathrm{S} / \mathrm{R}$ 3:1. As etapas de recuperação e repetitividade foram também avaliadas com esta mesma concentração.

Valores de LQM na faixa de 0,002 a $0,009 \mathrm{mg} \mathrm{kg}^{-1}$ foram obtidos para a maioria dos agrotóxicos avaliados (cerca de $57 \%$ ) para a faixa de 0,01 a $0,09 \mathrm{mg} \mathrm{kg}^{-1}$ (cerca de 44\%). O agrotóxico iodofenfós apresentou LQM de $0,430 \mathrm{mg} \mathrm{kg}^{-1}$, valor muito acima do LQM adequado a uma análise de resíduos, fato que deve estar relacionado à baixa seletividade do detector FPD, no modo fósforo (P), ao agrotóxico que possui somente um $\mathrm{P}$ em sua molécula. Novas avaliações poderão ser feitas para a substância no mesmo sistema de detecção (FPD) no modo enxofre $(\mathrm{S})$, pois o agrotóxico possui dois $\mathrm{S}$ em sua molécula.

O iodofenfós tem uso permitido em produtos domissanitários, não sendo indicado para uso em currais e/ou instalações leiteiras.

Considerando que alguns agrotóxicos (Tabela 1) apresentaram valores de LQM inferiores ao menor ponto da curva analítica, adotou-se o valor de $0,01 \mathrm{mg} \mathrm{kg}^{-1}$ como LQM, para todos os analitos avaliados na determinação rotineira desta matriz.

\section{Recuperação e repetitividade}

Os resultados da recuperação e da repetitividade das seis replicatas dos agrotóxicos presentes nas $\mathrm{S} 1$ e S2 nas concentrações 0,01 e $0,10 \mathrm{mg} \mathrm{kg}^{-1}$ encontram-se na Tabela 3 . Os valores de recuperação referentes à média das replicatas foram adequados para todos os agrotóxicos avaliados (faixa 70 a $120 \%$ ), exceto para o diclorvós. Ainda para o diclorvós foi testada a concentração de $0,097 \mathrm{mg} \mathrm{kg}^{-1}$; nesta concentração os valores de recuperação também não se mostraram adequados.

Com essa avaliação foi possível demonstrar que os LQM obtidos para os organofosforados são adequados, pois os valores dos desvios padrão e os coeficientes de variação obtidos, na recuperação e repetitividade, foram compatíveis com os parâmetros da SANCO. ${ }^{13}$

\section{CONCLUSÃO}

O método QuEChERS mostrou-se eficiente para 52 agrotóxicos e/ou derivados dentre os 53 avaliados nas matrizes leite integral e pasteurizado. Os LQM obtidos mostraram-se capazes de atender às especificações do MAPA ${ }^{19}$ no que se refere aos LMRs. Como não foram obtidos resultados satisfatórios para o diclorvós e, tendo em vista ser um agrotóxico muito utilizado em medicina veterinária e que seus resíduos podem contaminar o leite consumido pela população, estudos deverão ser feitos para a implantação de um método analítico adequado à sua análise.

\section{MATERIAL SUPLEMENTAR}

Está disponível em http://quimicanova.sbq.org.br, na forma de arquivo PDF, com acesso livre. A Tabela $1 \mathrm{~S}$ apresenta o efeito matriz identificado na matriz leite por organofosforados para os 5 níveis de concentração estudados. A Tabela $2 \mathrm{~S}$ apresenta resultados de recuperação (\%) obtidos no leite em 6 diferentes combinações de sorventes, para os organofosforados estudados. A Tabela 3S apresenta a representação da equação da reta e regressão, coeficientes de determinação para as faixas de trabalho estudadas e avaliação da homogeneidade da variância dos resíduos da regressão da curva analítica no extrato orgânico em leite para os agrotóxicos estudados.

\section{AGRADECIMENTOS}

Ao Conselho Nacional de Desenvolvimento Científico e Tecnológico (CNPQ) e à Fundação de Estudos e Projetos do Ministério da Ciência e Tecnologia (FINEP).

\section{REFERÊNCIAS}

1. Sampaio, I. A.; comunicação pessoal.

2. Melgar, M. J.; Santaeufemia, M.; Garcia, A. M. J.; J.Environ. Sci. Health, Part B 2010, 45, 595.

3. Jardim, A. N. O.; Caldas, E. D.; Quim. Nova 2009, 32, 1898.

4. Kan, A. C.; R. Bras. Zootec. 2009, 38, 423.

5. Bastos, L. H. P.; Cardoso, M. H. W. M.; Nóbrega, A. W.; Jacob, S. C.; Cad. Saúde Colet. 2011,19, 51.

6. http://www.anvisa.gov.br, acessada em Abril 2012.

7. Prestes, D. O.; Adaime, M. B.; Zanella, R.; Scientia Chromatographica 2011, 3, 51 .

8. Prestes, D. O.; Friggi, C. A .; Adaime, M. B.; Zanella, R.; Quim. Nova 2009, 32, 1620

9. Anastassiades, M.; Lehotay, S. J.; Stajnbaher, D.; Schenck, F. J.; J. AOAC Int. 2003, 86, 412

10. Lehotay, S. J.; Mástovská, K.; Ligtfield, R.; J. AOAC Int. 2005, 88, 615.

11. Jeong, I-S.; Kwak, B-M.; Jeong, S-H.; Food Chem. 2012, 133, 473.

12. Lehotay, S. J.; Mástovská, K.; J. AOAC Int. 2005, 88, 630.

13. European Community; Method validation and quality control procedures for pesticide residues analysis in food and feed, Document $\mathrm{N}^{\circ}$ SANCO/ 2009/10684, Sweden, 2009.

14. United States Department of Agriculture; Chemical Compounds, PDP Commodity Grouping, Method Validation and Quality Control SOP No PDP-QC. 2010, Rev 01, Washington, 2010.

15. Thompson, M.; Ellison, S. L. R.; Wood, R.; Pure Appl. Chem. 2006, 78, 145.

16. Cardoso, M. H. W.; Gouvêa, A. V.; Nóbrega, A. W.; Abrantes, S. M. P.; Ciênc. Tecnol. Aliment. 2010, 30, 63.

17. Codex Alimentarius Comission; Pesticide residues in food: methods of analysis and sampling, $2^{\text {nd }}$ ed., 2000, vol. 2A, part 1, Rome.

18. http://www.sindan.org.br, acessada em Abril 2012.

19. Ministério da Agricultura, Pecuária e Abastecimento; Instrução Normativa n 24, Diário Oficial da União, 11 de agosto de 2011, n 154. 


\section{IMPLEMENTAÇÃO DE MÉTODO ANALÍTICO PARA DETERMINAÇÃO DE RESÍDUOS DE ORGANOFOSFORADOS EM LEITE POR CROMATOGRAFIA A GÁS COM DETECTOR FOTOMÉTRICO DE CHAMA}

Lucia Helena Pinto Bastos*, Adherlene Vieira Gouvêa, Fabíola Málaga, Maria Helena Wohlers Morelli Cardoso, Silvana do Couto Jacob e Armi Wanderley da Nóbrega

Departamento de Química, Instituto Nacional de Controle de Qualidade em Saúde, Fundação Oswaldo Cruz, Av. Brasil, 4365, 21045-900 Rio de Janeiro - RJ, Brasil

Tabela 1S. Efeito matriz identificado na matriz leite, por organofosforados, para os 5 níveis avaliados

\begin{tabular}{|c|c|c|c|c|c|}
\hline \multirow{2}{*}{ Agrotóxicos } & \multicolumn{5}{|c|}{ Níveis $\mu \mathrm{g} \mathrm{mL}^{-1}$} \\
\hline & 0,01 & 0,02 & 0,03 & 0,04 & 0,05 \\
\hline Carbofenotiona, e dissulfotom & & & & $\mathrm{X}$ & $\mathrm{X}$ \\
\hline Clorpirifós e malationa & & $\mathrm{X}$ & & & $\mathrm{X}$ \\
\hline Clorpirifós metil, dissulfotom & & & & & $\mathrm{X}$ \\
\hline Diazinona, etiona, fenitrotiona, izasofós e parationa-metílica & & & $\mathrm{X}$ & & \\
\hline Diclorvós (DDVP), etrinfos, forato & & & & & $\mathrm{X}$ \\
\hline Dissulfotom-S- sulfurom & & & $\mathrm{X}$ & $\mathrm{X}$ & \\
\hline Fosalona e iodofenfós & & $\mathrm{X}$ & $\mathrm{X}$ & $\mathrm{X}$ & \\
\hline Mevinfós e sulfoprofós & & $\mathrm{X}$ & $\mathrm{X}$ & & $\mathrm{X}$ \\
\hline Pirazofos & $\mathrm{X}$ & & $\mathrm{X}$ & $\mathrm{X}$ & $\mathrm{X}$ \\
\hline Tebupirifós & & $\mathrm{X}$ & & & \\
\hline Metidationa & $\mathrm{X}$ & & $\mathrm{X}$ & $\mathrm{X}$ & \\
\hline Bromofós-etílico e metílico, pirimifós-metil e tiometona & & & & $\mathrm{X}$ & \\
\hline Clorfenvinfós & $\mathrm{X}$ & & & $\mathrm{X}$ & $\mathrm{X}$ \\
\hline Iodofenfós & & $\mathrm{X}$ & $\mathrm{X}$ & & $\mathrm{X}$ \\
\hline
\end{tabular}

$\mathrm{X}$ : indica presença de efeito matriz no nível estudado em $\mu \mathrm{g} \mathrm{mL}^{-1}$. 
Tabela 2S. Resultados de recuperação (\%), obtidos no leite, dos agrotóxicos estudados, em 6 diferentes combinações de sorventes estudadas (representadas de A a F)

\begin{tabular}{|c|c|c|c|c|c|c|c|}
\hline Agrotóxico & $\begin{array}{c}\text { Conc. adicionada } \\
\mu \mathrm{g} \mathrm{kg}^{-1}\end{array}$ & $\begin{array}{l}\mathrm{A} \\
\%\end{array}$ & $\begin{array}{l}\mathrm{B} \\
\%\end{array}$ & $\begin{array}{l}\mathrm{C} \\
\% \\
\end{array}$ & $\begin{array}{l}\mathrm{D} \\
\% \\
\end{array}$ & $\begin{array}{l}\mathrm{E} \\
\% \\
\end{array}$ & $\begin{array}{l}\mathrm{F} \\
\%\end{array}$ \\
\hline Acefato & 0,068 & 69 & 72 & 83 & 54 & 99 & 65 \\
\hline Azinfós-etílico & 0,066 & 76 & 89 & 92 & 69 & 108 & 85 \\
\hline Azinfós-metilico & 0,066 & 70 & 81 & 77 & 59 & 93 & 74 \\
\hline Bromofós-etílico & 0,065 & 72 & 65 & 81 & 62 & 97 & 76 \\
\hline Bromofós-metílico & 0,104 & 70 & 72 & 84 & 65 & 98 & 82 \\
\hline Carbofenotiona & 0,066 & 83 & 70 & 94 & 68 & 99 & 83 \\
\hline Clorfenvinfós & 0,071 & 67 & 67 & 65 & 56 & 81 & 63 \\
\hline Clorpirifós & 0,076 & 82 & 84 & 84 & 68 & 98 & 86 \\
\hline Clorpirifós metílico & 0,073 & 75 & 83 & 93 & 65 & 104 & 88 \\
\hline Demetom-S-metílico & 0,079 & 70 & 72 & 87 & 62 & 102 & 77 \\
\hline Diazinona & 0,089 & 68 & 68 & 82 & 60 & 93 & 76 \\
\hline Diclorvós* (DDVP) & 0,091 & 41 & 43 & 43 & 20 & 42 & 35 \\
\hline Dimetoato & 0,063 & 83 & 66 & 66 & 68 & 76 & 78 \\
\hline Dissulfotom & 0,090 & 65 & 63 & 77 & 59 & 90 & 71 \\
\hline Dissulfotom-S-sulfuron & 0,054 & 70 & 78 & 87 & 65 & 96 & 79 \\
\hline Etiona & 0,096 & 68 & 68 & 81 & 62 & 95 & 77 \\
\hline Etoprofós & 0,085 & 65 & 66 & 64 & 52 & 76 & 68 \\
\hline Etrinfos & 0,070 & $\mathrm{Na}$ & $\mathrm{Na}$ & $\mathrm{Na}$ & $\mathrm{Na}$ & 101 & $\mathrm{Na}$ \\
\hline Fenamifós & 0,056 & 90 & 92 & 90 & 63 & 110 & 88 \\
\hline Fenitrotiona & 0,073 & 75 & 79 & 89 & 70 & 104 & 81 \\
\hline Fentiona & 0,081 & 63 & 66 & 66 & 53 & 84 & 68 \\
\hline Forato & 0,081 & 62 & 61 & 61 & 49 & 73 & 65 \\
\hline Fosalona & 0,063 & 87 & 93 & 118 & 82 & 114 & 100 \\
\hline Fosfamidona & 0,084 & 92 & 97 & 97 & 71 & 108 & 95 \\
\hline Fosmete & 0,067 & 64 & 79 & 76 & 51 & 95 & 76 \\
\hline Formotiona & 0,075 & 55 & 116 & 116 & 36 & 87 & 68 \\
\hline Iodofenfós & 0,062 & 84 & 85 & 86 & 73 & 110 & 99 \\
\hline Iodofenfós & 0,062 & 84 & 85 & 86 & 73 & 110 & 99 \\
\hline Izasofós & 0,095 & 83 & 80 & 98 & 72 & 112 & 89 \\
\hline Malaoxon & 0,063 & 81 & 86 & 86 & 63 & 96 & 84 \\
\hline Malationa & 0,076 & 66 & 73 & 73 & 56 & 89 & 72 \\
\hline Metamidofós & 0,085 & 65 & 70 & 81 & 53 & 83 & 60 \\
\hline Metidationa & 0,046 & 72 & 76 & 84 & 63 & 101 & 84 \\
\hline Mevinfós & 0,108 & 73 & 73 & 73 & 55 & 83 & 69 \\
\hline Monocrotofós & 0,058 & 91 & 89 & 89 & 62 & 101 & 79 \\
\hline Nalede & 0,074 & 64 & 52 & 66 & 56 & 86 & 87 \\
\hline Ometoato & 0,071 & 66 & 66 & 86 & 56 & 88 & 70 \\
\hline Paraoxon etílico & 0,089 & 90 & 94 & 109 & 79 & 112 & 100 \\
\hline Paraoxon metílico & 0,103 & 77 & 48 & 86 & 51 & 91 & 70 \\
\hline Parationa-etílica & 0,064 & 74 & 79 & 91 & 69 & 102 & 86 \\
\hline Parationa-metílica & 0,064 & 150 & 153 & 179 & 130 & 111 & 176 \\
\hline Pirazofós & 0,077 & 77 & 82 & 91 & 72 & 110 & 88 \\
\hline Piridafentiona & 0,067 & 82 & 84 & 84 & 68 & 104 & 86 \\
\hline Pirimifós-etílico & 0,065 & 75 & 75 & 75 & 67 & 99 & 79 \\
\hline Pirimifós-metílico & 0,069 & 98 & 88 & 104 & 84 & 111 & 148 \\
\hline Profenofós & 0,060 & 70 & 76 & 83 & 58 & 90 & 245 \\
\hline Protiofós & 0,069 & 113 & 108 & 126 & 103 & 104 & 129 \\
\hline Sulfoprós & 0,065 & 77 & 77 & 77 & 70 & 90 & 75 \\
\hline Terbufós & 0,063 & 91 & 91 & 91 & 76 & 118 & 97 \\
\hline Tebupirinfós & 0,085 & 77 & 77 & 77 & 64 & 95 & 81 \\
\hline Tetraclorvinfós & 0,063 & 79 & 75 & 75 & 63 & 106 & 72 \\
\hline Tiometona & 0,067 & 64 & 68 & 79 & 58 & 95 & 74 \\
\hline Triazofós & 0,063 & 95 & 101 & 97 & 83 & 95 & 101 \\
\hline Vamidotiona & 0,088 & 116 & 133 & 116 & 66 & 111 & 116 \\
\hline
\end{tabular}

Na: Não avaliado.* Recuperação baixa todas as combinações. 
Tabela 3S. Representação da equação da reta e regressão, coeficientes de determinação para as faixas de trabalho estudadas e avaliação da homogeneidade da variância dos resíduos da regressão da curva analítica no extrato orgânico em leite para os 53 organofosforados estudados

\begin{tabular}{|c|c|c|c|c|c|c|}
\hline Agrotóxico e estatísticas & $\begin{array}{c}\text { Faixa linear } \\
\mu \mathrm{g} \mathrm{mL} \mathrm{mL}^{-1}\end{array}$ & Equação da regressão & $\mathrm{R}^{2}$ & $\mathrm{C}_{\text {calculado }}$ & $\begin{array}{l}\text { C tabelado } \\
\mathrm{k}=5, \mathrm{n}=2\end{array}$ & Resultados \\
\hline $\begin{array}{l}\text { Acefato } \\
\text { Anova teste F } \\
\text { Anova falta de ajuste }\end{array}$ & 0,011 a 0,056 & $\begin{array}{c}\mathrm{y}=3608,6907-14,5872 \\
\mathrm{~F}_{\text {calculado }}(525,9873)>\text { valor } \mathrm{p}\left(6,708 * 10^{-12}\right)\end{array}$ & 0,976 & 0,595 & 0,684 & $\begin{array}{c}\text { Homoscedástico } \\
\text { Significante }\end{array}$ \\
\hline $\begin{array}{l}\text { Azinfós-etílico } \\
\text { Anova teste F } \\
\text { Anova falta de ajuste }\end{array}$ & 0,011 a 0,053 & $\begin{array}{c}\mathrm{y}=2579,4604 \mathrm{x}-2,7606 \\
\mathrm{~F}_{\text {calculado }}(775,2435)>\text { valor } \mathrm{p}\left(5,651 * 10^{-13}\right)\end{array}$ & 0,984 & 0,431 & 0,684 & $\begin{array}{c}\text { Homoscedástico } \\
\text { Significante }\end{array}$ \\
\hline $\begin{array}{l}\text { Azinfós-metilico } \\
\text { Anova teste F } \\
\text { Anova falta de ajuste } \\
\end{array}$ & 0,011 a 0,053 & $\begin{array}{c}\mathrm{y}=2529,6020 \mathrm{x}+0,2548 \\
\mathrm{~F}_{\text {calculado }}(591,2248)>\text { valor } \mathrm{p}\left(3,188^{*} 10^{-12}\right)\end{array}$ & 0,978 & 0,431 & 0,684 & $\begin{array}{c}\text { Homoscedástico } \\
\text { Significante } \\
\end{array}$ \\
\hline $\begin{array}{l}\text { Bromofós- etílico } \\
\text { Anova teste F } \\
\text { Anova falta de ajuste } \\
\end{array}$ & 0,052 a 0,2620 & $\begin{array}{c}\mathrm{y}=4003,1161 \mathrm{x}+4,1636 \\
\mathrm{~F}_{\text {calculado }}(767,4118)>\text { valor } \mathrm{p}\left(6030 * 10^{-13}\right)\end{array}$ & 0,983 & 0,566 & 0,684 & $\begin{array}{c}\text { Homoscedástico } \\
\text { Significante } \\
\end{array}$ \\
\hline $\begin{array}{l}\text { Bromofós-metílico } \\
\text { Anova teste F } \\
\text { Anova falta de ajuste }\end{array}$ & 0,014 a 0,068 & $\begin{array}{c}\mathrm{y}=3749,6160 \mathrm{x}+1,9106 \\
\mathrm{~F}_{\text {calculado }}(519,5733)>\text { valor } \mathrm{p}\left(7,252 * 10^{-12}\right)\end{array}$ & 0,976 & 0,580 & 0,684 & $\begin{array}{c}\text { Homoscedástico } \\
\text { Significante }\end{array}$ \\
\hline $\begin{array}{l}\text { Carbofenotiona } \\
\text { Anova teste F } \\
\text { Anova falta de ajuste } \\
\end{array}$ & 0,011 a 0,053 & $\begin{array}{c}\mathrm{y}=3032,5727 \mathrm{x}-0,0650 \\
\mathrm{~F}_{\text {calculado }}(456,0078)>\text { valor } \mathrm{p}\left(1,659 * 10^{-11}\right)\end{array}$ & 0,972 & 0,450 & 0,684 & $\begin{array}{c}\text { Homoscedástico } \\
\text { Significante }\end{array}$ \\
\hline $\begin{array}{l}\text { Clorfenvinfós } \\
\text { Anova teste F } \\
\text { Anova falta de ajuste }\end{array}$ & 0,015 a 0,075 & $\begin{array}{c}\mathrm{y}=2590,2060 \mathrm{x}+3,6448 \\
\mathrm{~F}_{\text {calculado }}(824,2578)>\text { valor } \mathrm{p}\left(3,816^{*} 10^{-13}\right)\end{array}$ & 0,984 & 0,381 & 0,684 & $\begin{array}{c}\text { Homoscedástico } \\
\text { Significante }\end{array}$ \\
\hline $\begin{array}{l}\text { *Clorpirifós ( } 3 \text { pontos) } \\
\text { Anova teste } \mathrm{F} \\
\text { Anova falta de ajuste }\end{array}$ & 0,020 a 0,041 & $\begin{array}{c}\mathrm{y}=4286,684033 \mathrm{x}+19,381250 \\
\mathrm{~F}_{\text {calculado }}(306,5369)>\text { valor } \mathrm{p}\left(4,882 * 10^{-7}\right)\end{array}$ & 0,978 & 0,597 & $\begin{array}{c}\mathrm{K}=3, \mathrm{n}=2 \\
0,871\end{array}$ & $\begin{array}{c}\text { Homoscedástico } \\
\text { Significante }\end{array}$ \\
\hline $\begin{array}{l}\text { Clorpirifós-metil } \\
\text { Anova teste F } \\
\text { Anova falta de ajuste } \\
\end{array}$ & 0,012 a 0,060 & $\begin{array}{c}\mathrm{y}=40378575 \mathrm{x}+8,4351 \\
\mathrm{~F}_{\text {calculado }}(855,0984)>\text { valor } \mathrm{p}\left(1,659 * 10^{-11}\right)\end{array}$ & 0,985 & 0,607 & 0,684 & $\begin{array}{c}\text { Homoscedástico } \\
\text { Significante }\end{array}$ \\
\hline $\begin{array}{l}\text { Demeton S metil } \\
(3 \text { pontos) } \\
\text { Anova teste F } \\
\text { Anova falta de ajuste }\end{array}$ & 0,011 a 0,054 & $\begin{array}{c}\mathrm{y}=5502,0713 \mathrm{x}+1,7845 \\
\mathrm{~F}_{\text {calculado }}(0,72428)>\text { valor } \mathrm{p}\left(1,659 * 10^{-11}\right)\end{array}$ & 0,978 & 0,724 & $\begin{array}{c}\mathrm{K}=3, \mathrm{n}=2 \\
0,871\end{array}$ & $\begin{array}{c}\text { Homoscedástico } \\
\text { Significante } \\
\end{array}$ \\
\hline $\begin{array}{l}\text { Diazinona } \\
\text { Anova teste F } \\
\text { Anova falta de ajuste } \\
\end{array}$ & 0,014 a 0,071 & $\begin{array}{c}\mathrm{y}=4771,2734 \mathrm{x}+2,1427 \\
\mathrm{~F}_{\text {calculado }}(529,3397)>\text { valor } \mathrm{p}\left(6,442 * 10^{-12}\right)\end{array}$ & 0,976 & 0,664 & 0,684 & $\begin{array}{c}\text { Homoscedástico } \\
\text { Significante } \\
\end{array}$ \\
\hline $\begin{array}{l}\text { Dissulfotom S. Sulfurom } \\
\text { Anova teste F } \\
\text { Anova falta de ajuste } \\
\end{array}$ & 0,015 a 0,0077 & $\begin{array}{c}\mathrm{y}=3267,3889 \mathrm{x}+0,7105 \\
\mathrm{~F}_{\text {calculado }}(823,4276)>\text { valor } \mathrm{p}\left(3,841^{*} 10^{-13}\right)\end{array}$ & 0,984 & 0,604 & 0,684 & $\begin{array}{c}\text { Homoscedástico } \\
\text { Significante }\end{array}$ \\
\hline $\begin{array}{l}\text { *Diclorvós ( } 3 \text { pontos) } \\
\text { Anova teste } \mathrm{F} \\
\text { Anova falta de ajuste } \\
\end{array}$ & 0,029 a 0,058 & $\begin{array}{c}\mathrm{y}=4888,355843 \mathrm{x}+7,243346 \\
\mathrm{~F}_{\text {calculado }}(348,9783)>\text { valor } \mathrm{p}\left(3,127 * 10^{-7}\right)\end{array}$ & 0,980 & 0,498 & $\begin{array}{c}\mathrm{K}=3, \mathrm{n}=2 \\
0,871\end{array}$ & $\begin{array}{c}\text { Homoscedástico } \\
\text { Significante }\end{array}$ \\
\hline $\begin{array}{l}\text { Dimetoato } \\
\text { Anova teste F } \\
\text { Anova falta de ajuste }\end{array}$ & 0,010 a 0,051 & $\begin{array}{c}\mathrm{y}=5512,6832 \mathrm{x}+2,7054 \\
\mathrm{~F}_{\text {calculado }}(891,6945)>\text { valor } \mathrm{p}\left(2,305^{*} 10^{-13}\right)\end{array}$ & 0,986 & 0,606 & 0,684 & $\begin{array}{c}\text { Homoscedástico } \\
\text { Significante }\end{array}$ \\
\hline $\begin{array}{l}\text { Dissulfotom } \\
\text { Anova teste F } \\
\text { Anova falta de ajuste }\end{array}$ & 0,011 a 0,053 & $\begin{array}{c}\mathrm{y}=5001,9994 \mathrm{x}+1,5532 \\
\mathrm{~F}_{\text {calculado }}(660,5998)>\text { valor } \mathrm{p}\left(1,571 * 10^{-12}\right)\end{array}$ & 0,981 & 0,566 & 0,684 & $\begin{array}{c}\text { Homoscedástico } \\
\text { Significante }\end{array}$ \\
\hline $\begin{array}{l}\text { Etiona } \\
\text { Anova teste F } \\
\text { Anova falta de ajuste }\end{array}$ & 0,015 a 0,077 & $\begin{array}{c}\mathrm{y}=5691,6645 \mathrm{x}+2,6960 \\
\mathrm{~F}_{\text {calculado }}(636,2618)>\text { valor } \mathrm{p}\left(1,997 * 10^{-12}\right)\end{array}$ & 0,980 & 0,546 & 0,684 & $\begin{array}{c}\text { Homoscedástico } \\
\text { Significante }\end{array}$ \\
\hline $\begin{array}{l}\text { Etoprofós } \\
\text { Anova teste F } \\
\text { Anova falta de ajuste }\end{array}$ & 0,014 a 0,068 & $\begin{array}{c}\mathrm{y}=5281,221 \mathrm{x}+2,3842 \\
\mathrm{~F}_{\text {calculado }}(786,5748)>\text { valor } \mathrm{p}\left(5,149 * 10^{-13}\right)\end{array}$ & 0,984 & 0,662 & 0,684 & $\begin{array}{c}\text { Homoscedástico } \\
\text { Significante }\end{array}$ \\
\hline $\begin{array}{l}\text { *Etrinfos ( } 3 \text { pontos) } \\
\text { Anova teste } \mathrm{F} \\
\text { Anova falta de ajuste }\end{array}$ & 0,026 a 0,042 & $\begin{array}{c}\mathrm{y}=9740,973163 \mathrm{x}-72,139209 \\
\mathrm{~F}_{\text {calculado }}(521,4785)>\text { valor } \mathrm{p}\left(7,824 * 10^{-8}\right)\end{array}$ & 0,987 & 0,395 & $\begin{array}{c}\mathrm{K}=3, \mathrm{n}=2 \\
0,871\end{array}$ & $\begin{array}{c}\text { Homoscedástico } \\
\text { Significante }\end{array}$ \\
\hline $\begin{array}{l}\text { Fenamifós } \\
\text { Anova teste F } \\
\text { Anova falta de ajuste } \\
\end{array}$ & 0,009 a 0,045 & $\begin{array}{c}\mathrm{y}=3735,5422 \mathrm{x}+1,4283 \\
\mathrm{~F}_{\text {calculado }}(432,3369)>\text { valor } \mathrm{p}\left(2,325^{*} 10^{-11}\right)\end{array}$ & 0,971 & 0,358 & 0,684 & $\begin{array}{c}\text { Homoscedástico } \\
\text { Significante } \\
\end{array}$ \\
\hline $\begin{array}{l}\text { Fenitrotiona } \\
\text { Anova teste F } \\
\text { Anova falta de ajuste }\end{array}$ & 0,012 a 0,058 & $\begin{array}{c}\mathrm{y}=5106,7708 \mathrm{x}+1,1467 \\
\mathrm{~F}_{\text {calculado }}(823,8957)>\text { valor } \mathrm{p}\left(3,827 * 10^{-13}\right)\end{array}$ & 0,984 & 0,664 & 0,684 & $\begin{array}{c}\text { Homoscedástico } \\
\text { Significante }\end{array}$ \\
\hline
\end{tabular}


Tabela 3S. continuação

\begin{tabular}{|c|c|c|c|c|c|c|}
\hline Agrotóxico e estatísticas & $\begin{array}{c}\text { Faixa linear } \\
\mu \mathrm{g} \mathrm{mL} L^{-1}\end{array}$ & Equação da regressão & $\mathrm{R}^{2}$ & $\mathrm{C}_{\text {calculado }}$ & $\begin{array}{l}\mathrm{C} \text { tabelado } \\
\mathrm{k}=5, \mathrm{n}=2\end{array}$ & Resultados \\
\hline $\begin{array}{l}\text { Fentiona } \\
\text { Anova teste F } \\
\text { Anova falta de ajuste } \\
\end{array}$ & 0,011 a 0,057 & $\begin{array}{c}\mathrm{y}=4523,6247 \mathrm{x}+2,0826 \\
\mathrm{~F}_{\text {calculado }}(650,0337)>\text { valor } \mathrm{p}\left(1,742 * 10^{-12}\right)\end{array}$ & 0,981 & 0,510 & 0,684 & $\begin{array}{c}\text { Homoscedástico } \\
\text { Significante } \\
\end{array}$ \\
\hline $\begin{array}{l}\text { Forato ( } 3 \text { pontos) } \\
\text { Anova teste } F \\
\text { Anova falta de ajuste }\end{array}$ & 0,026 a 0,051 & $\begin{array}{c}\mathrm{y}=4691,4285 \mathrm{x}+5,415957 \\
\mathrm{~F}_{\text {calculado }}(883,5896)>\text { valor } \mathrm{p}\left(1,257 * 10^{-8}\right)\end{array}$ & 0,992 & 0,481 & $\begin{array}{c}K=3, n=2 \\
0,871\end{array}$ & $\begin{array}{c}\text { Homoscedástico } \\
\text { Significante } \\
\end{array}$ \\
\hline $\begin{array}{l}\text { Formotiona } \\
\text { Anova teste } \mathrm{F} \\
\text { Anova falta de ajuste } \\
\end{array}$ & 0,010 a 0,050 & $\begin{array}{c}\mathrm{y}=4323,5736 \mathrm{x}+1,3794 \\
\mathrm{~F}_{\text {calculado }}(955,6693)>\text { valor } \mathrm{p}\left(1,478^{*} 10^{-13}\right)\end{array}$ & 0,986 & 0,473 & 0,684 & $\begin{array}{c}\text { Homoscedástico } \\
\text { Significante } \\
\end{array}$ \\
\hline $\begin{array}{l}\text { Fosfamidona } \\
\text { Anova teste F } \\
\text { Anova falta de ajuste } \\
\end{array}$ & 0,011 a 0,054 & $\begin{array}{c}\mathrm{y}=2590,3503 \mathrm{x}+0,3034 \\
\mathrm{~F}_{\text {calculado }}(702,0656)>\text { valor } \mathrm{p}\left(1,065^{*} 10^{-12}\right)\end{array}$ & 0,982 & 0,510 & 0,684 & $\begin{array}{c}\text { Homoscedástico } \\
\text { Significante } \\
\end{array}$ \\
\hline $\begin{array}{l}\text { Fosalona } \\
\text { Anova teste F } \\
\text { Anova falta de ajuste } \\
\end{array}$ & 0,010 a 0,051 & $\begin{array}{c}\mathrm{y}=2716,957 \mathrm{x}+0,6514 \\
\mathrm{~F}_{\text {calculado }}(653,2523)>\text { valor } \mathrm{p}\left(1,688 * 10^{-12}\right)\end{array}$ & 0,982 & 0,491 & 0,684 & $\begin{array}{c}\text { Homoscedástico } \\
\text { Significante } \\
\end{array}$ \\
\hline $\begin{array}{l}\text { Fosmete } \\
\text { Anova teste F } \\
\text { Anova falta de ajuste } \\
\end{array}$ & 0,011 a 0,053 & $\begin{array}{c}\mathrm{y}=2843,8585 \mathrm{x}+2,9419 \\
\mathrm{~F}_{\text {calculado }}(550,247)>\text { valor } \mathrm{p}\left(5,032 * 10^{-12}\right)\end{array}$ & 0,977 & 0,319 & 0,684 & $\begin{array}{c}\text { Homoscedástico } \\
\text { Significante } \\
\end{array}$ \\
\hline $\begin{array}{l}\text { Iodofenfós } \\
\text { Anova teste F } \\
\text { Anova falta de ajuste } \\
\end{array}$ & 0,011 a 0,050 & $\begin{array}{c}\mathrm{y}=3222,1890 \mathrm{x}-0,0156 \\
\mathrm{~F}_{\text {calculado }}(444,3066)>\text { valor } \mathrm{p}\left(1,956 * 10^{-11}\right)\end{array}$ & 0,971 & 0,510 & 0,684 & $\begin{array}{c}\text { Homoscedástico } \\
\text { Significante } \\
\end{array}$ \\
\hline $\begin{array}{l}\text { Isazofós } \\
\text { Anova teste F } \\
\text { Anova falta de ajuste } \\
\end{array}$ & 0,01 a 0,048 & $\begin{array}{c}\mathrm{y}=4684,4303 \mathrm{x}+8,1952 \\
\mathrm{~F}_{\text {calculado }}(516,1696)>\text { valor } \mathrm{p}\left(7,561 * 10^{-12}\right)\end{array}$ & 0,975 & 0,631 & 0,684 & $\begin{array}{c}\text { Homoscedástico } \\
\text { Significante } \\
\end{array}$ \\
\hline $\begin{array}{l}\text { Malaoxon } \\
\text { Anova teste F } \\
\text { Anova falta de ajuste } \\
\end{array}$ & 0,010 a 0,050 & $\begin{array}{c}\mathrm{y}=3251,5715 \mathrm{x}+6,0906 \\
\mathrm{~F}_{\text {calculado }}(893,0895)>\text { valor } \mathrm{p}\left(2,282 * 10^{-13}\right)\end{array}$ & 0,986 & 0,543 & 0,684 & $\begin{array}{c}\text { Homoscedástico } \\
\text { Significante } \\
\end{array}$ \\
\hline $\begin{array}{l}\text { Malationa } \\
\text { Anova teste F } \\
\text { Anova falta de ajuste } \\
\end{array}$ & 0,011 a 0,057 & $\begin{array}{c}\mathrm{y}=3719,5395 \mathrm{x}+3,2411 \\
\mathrm{~F}_{\text {calculado }}(720,0988)>\text { valor } \mathrm{p}\left(9,059 * 10^{-13}\right)\end{array}$ & 0,982 & 0,528 & 0,684 & $\begin{array}{c}\text { Homoscedástico } \\
\text { Significante } \\
\end{array}$ \\
\hline $\begin{array}{l}\text { Meditadiona } \\
\text { Anova teste } \mathrm{F} \\
\text { Anova falta de ajuste } \\
\end{array}$ & 0,012 a 0,062 & $\begin{array}{c}\mathrm{y}=3619,1177 \mathrm{x}+5,5137 \\
\mathrm{~F}_{\text {calculado }}(764,5637)>\text { valor } \mathrm{p}\left(6,175^{*} 10^{-13}\right)\end{array}$ & 0,983 & 0,485 & 0,684 & $\begin{array}{c}\text { Homoscedástico } \\
\text { Significante } \\
\end{array}$ \\
\hline $\begin{array}{l}\text { Metamidofós } \\
\text { Anova teste F } \\
\text { Anova falta de ajuste }\end{array}$ & 0,014 a 0,068 & $\begin{array}{c}\mathrm{y}=7131,7611 \mathrm{x}-21,7667 \\
\mathrm{~F}_{\text {calculado }}(467,7296)>\text { valor } \mathrm{p}\left(1,413^{*} 10^{-11}\right)\end{array}$ & 0,973 & 0,529 & 0,684 & $\begin{array}{c}\text { Homoscedástico } \\
\text { Significante }\end{array}$ \\
\hline $\begin{array}{l}\text { *Mevinfós ( } 3 \text { pontos) } \\
\text { Anova teste } \mathrm{F} \\
\text { Anova falta de ajuste } \\
\end{array}$ & 0,023 a 0,047 & $\begin{array}{c}\mathrm{y}=3153,872083 \mathrm{x}+13,814593 \\
\mathrm{~F}_{\text {calculado }}(700,6748)>\text { valor } \mathrm{p}\left(2,812^{*} 10^{-8}\right)\end{array}$ & 0,990 & 0,433 & $\begin{array}{c}\mathrm{K}=3, \mathrm{n}=2 \\
0,871\end{array}$ & $\begin{array}{c}\text { Homoscedástico } \\
\text { Significante } \\
\end{array}$ \\
\hline $\begin{array}{l}\text { Monocrotofós } \\
\text { Anova teste F } \\
\text { Anova falta de ajuste } \\
\end{array}$ & 0,013 a 0,067 & $\begin{array}{c}\mathrm{y}=3168,3171 \mathrm{x}-2,2303 \\
\mathrm{~F}_{\text {calculado }}(521,8643)>\text { valor } \mathrm{p}\left(7,052^{*} 10^{-12}\right)\end{array}$ & 0,976 & 0,643 & 0,684 & $\begin{array}{c}\text { Homoscedástico } \\
\text { Significante } \\
\end{array}$ \\
\hline $\begin{array}{l}\text { Nalede ( } 3 \text { pontos) } \\
\text { Anova teste } \mathrm{F} \\
\text { Anova falta de ajuste } \\
\end{array}$ & 0,02 a 0,041 & $\begin{array}{c}\mathrm{y}=2114,138897 \mathrm{x}-13,403303 \\
\mathrm{~F}_{\text {calculado }}(235,9571)>\text { valor } \mathrm{p}\left(1,195^{*} 10^{-6}\right)\end{array}$ & 0,971 & 0,859 & $\begin{array}{l}\mathrm{K}=3, \mathrm{n}=2 \\
\quad 0,871\end{array}$ & $\begin{array}{c}\text { Homoscedástico } \\
\text { Significante } \\
\end{array}$ \\
\hline $\begin{array}{l}\text { Ometoato } \\
\text { Anova teste F } \\
\text { Anova falta de ajuste } \\
\end{array}$ & 0,011 a 0,056 & $\begin{array}{c}\mathrm{y}=2058,9907 \mathrm{x}-4,9230 \\
\mathrm{~F}_{\text {calculado }}(672,7437)>\text { valor } \mathrm{p}\left(1,399 * 10^{-12}\right)\end{array}$ & 0,981 & 0,981 & 0,684 & $\begin{array}{c}\text { Homoscedástico } \\
\text { Significante } \\
\end{array}$ \\
\hline $\begin{array}{l}\text { Paraoxon etílico } \\
\text { Anova teste F } \\
\text { Anova falta de ajuste } \\
\end{array}$ & 0,012 a 0,061 & $\begin{array}{c}\mathrm{y}=4051,5172 \mathrm{x}+9,0458 \\
\mathrm{~F}_{\text {calculado }}(333,4792)>\text { valor } \mathrm{p}\left(1,193 * 10^{-10}\right)\end{array}$ & 0,962 & 0,495 & 0,684 & $\begin{array}{c}\text { Homoscedástico } \\
\text { Significante } \\
\end{array}$ \\
\hline $\begin{array}{l}\text { Parationa etílica } \\
\text { Anova teste F } \\
\text { Anova falta de ajuste }\end{array}$ & 0,01 a 0,051 & $\begin{array}{c}\mathrm{y}=4368,3081 \mathrm{x}+20,1605 \\
\mathrm{~F}_{\text {calculado }}(286,3763)>\text { valor } \mathrm{p}\left(3,092^{*} 10^{-10}\right)\end{array}$ & 0,957 & 0,562 & 0,684 & $\begin{array}{c}\text { Homoscedástico } \\
\text { Significante } \\
\end{array}$ \\
\hline $\begin{array}{l}\text { Parationa-metílica } \\
\text { Anova teste F } \\
\text { Anova falta de ajuste }\end{array}$ & 0,01 a 0,05 & $\begin{array}{c}\mathrm{y}=5282,2749 \mathrm{x}+4,8874 \\
\mathrm{~F}_{\text {calculado }}(472,3859)>\text { valor } \mathrm{p}\left(1,327 * 10^{-11}\right)\end{array}$ & 0,973 & 0,674 & 0,684 & $\begin{array}{c}\text { Homoscedástico } \\
\text { Significante } \\
\end{array}$ \\
\hline $\begin{array}{l}\text { Pirazofós } \\
\text { Anova teste F } \\
\text { Anova falta de ajuste }\end{array}$ & 0,01 a 0,051 & $\begin{array}{c}\mathrm{y}=2508,7874 \mathrm{x}+1,8800 \\
\mathrm{~F}_{\text {calculado }}(472,3859)>\text { valor } \mathrm{p}\left(1,327 * 10^{-11}\right)\end{array}$ & 0,980 & 0,387 & 0,684 & $\begin{array}{c}\text { Homoscedástico } \\
\text { Significante } \\
\end{array}$ \\
\hline $\begin{array}{l}\text { Piridafentiona } \\
\text { Anova teste F } \\
\text { Anova falta de ajuste }\end{array}$ & 0,011 a 0,054 & $\begin{array}{c}\mathrm{y}=2896,6361 \mathrm{x}+0,5592 \\
\mathrm{~F}_{\text {calculado }}(536,9533)>\text { valor } \mathrm{p}\left(5,883^{*} 10^{-12}\right)\end{array}$ & 0,976 & 0,398 & 0,684 & $\begin{array}{c}\text { Homoscedástico } \\
\text { Significante } \\
\end{array}$ \\
\hline
\end{tabular}


Tabela 3S. continuação

\begin{tabular}{|c|c|c|c|c|c|c|}
\hline Agrotóxico e estatísticas & $\begin{array}{c}\text { Faixa linear } \\
\mu \mathrm{g} \mathrm{mL} \mathrm{mL}^{-1}\end{array}$ & Equação da regressão & $\mathrm{R}^{2}$ & $\mathrm{C}_{\text {calculado }}$ & $\begin{array}{l}\text { C tabelado } \\
\mathrm{k}=5, \mathrm{n}=2\end{array}$ & Resultados \\
\hline $\begin{array}{l}\text { Pirimifós-etílico } \\
\text { Anova teste F } \\
\text { Anova falta de ajuste } \\
\end{array}$ & 0,010 a 0,052 & $\begin{array}{c}\mathrm{y}=3899,2294 \mathrm{x}+6,5209 \\
\mathrm{~F}_{\text {calculado }}(547,5987)>\text { valor } \mathrm{p}\left(5,193 * 10^{-12}\right)\end{array}$ & 0,977 & 0,666 & 0,684 & $\begin{array}{c}\text { Homoscedástico } \\
\text { Significante }\end{array}$ \\
\hline $\begin{array}{l}\text { Pirimifós-metílico } \\
\text { Anova teste F } \\
\text { Anova falta de ajuste } \\
\end{array}$ & 0,01 a 0,053 & $\begin{array}{c}\mathrm{y}=4123,0249 \mathrm{x}+4,3524 \\
\mathrm{~F}_{\text {calculado }}(506,2561)>\text { valor } \mathrm{p}\left(8,551 * 10^{-12}\right)\end{array}$ & 0,975 & 0,470 & 0,684 & $\begin{array}{c}\text { Homoscedástico } \\
\text { Significante } \\
\end{array}$ \\
\hline $\begin{array}{l}\text { Profenofós } \\
\text { Anova teste F } \\
\text { Anova falta de ajuste } \\
\end{array}$ & 0,011 a 0,053 & $\begin{array}{c}\mathrm{y}=2622,2221 \mathrm{x}+5,2219 \\
\mathrm{~F}_{\text {calculado }}(532,4880)>\text { valor } \mathrm{p}\left(6,204 * 10^{-12}\right)\end{array}$ & 0,976 & 0,638 & 0,684 & $\begin{array}{c}\text { Homoscedástico } \\
\text { Significante } \\
\end{array}$ \\
\hline $\begin{array}{l}\text { Protiofós } \\
\text { Anova teste F } \\
\text { Anova falta de ajuste } \\
\end{array}$ & 0,01 a 0,05 & $\begin{array}{c}\mathrm{y}=3256,1213 \mathrm{x}+1,1661 \\
\mathrm{~F}_{\text {calculado }}(1023,6405)>\text { valor } \mathrm{p}\left(9,507 * 10^{-14}\right)\end{array}$ & 0,987 & 0,508 & 0,684 & $\begin{array}{c}\text { Homoscedástico } \\
\text { Significante }\end{array}$ \\
\hline $\begin{array}{l}\text { Sulprofós } \\
\text { Anova teste F } \\
\text { Anova falta de ajuste } \\
\end{array}$ & 0,01 a 0,052 & $\begin{array}{c}\mathrm{y}=3218,7019 \mathrm{x}+1,9930 \\
\mathrm{~F}_{\text {calculado }}(615,1118)>\text { valor } \mathrm{p}\left(2,477 * 10^{-12}\right)\end{array}$ & 0,979 & 0,268 & 0,684 & $\begin{array}{c}\text { Homoscedástico } \\
\text { Significante } \\
\end{array}$ \\
\hline $\begin{array}{l}\text { *Terbufós ( } 3 \text { pontos) } \\
\text { Anova teste } \mathrm{F} \\
\text { Anova falta de ajuste } \\
\end{array}$ & 0,024 a 0,049 & $\begin{array}{c}\mathrm{y}=3906,192569 \mathrm{x}+17,206566 \\
\mathrm{~F}_{\text {calculado }}(1409,8103)>\text { valor } \mathrm{p}\left(2,472 * 10^{-9}\right)\end{array}$ & 0,995 & 0,747 & $\begin{array}{c}\mathrm{K}=3, \mathrm{n}=2 \\
0,871\end{array}$ & $\begin{array}{c}\text { Homoscedástico } \\
\text { Significante }\end{array}$ \\
\hline $\begin{array}{l}\text { Tebupirinfós } \\
\text { Anova teste F } \\
\text { Anova falta de ajuste } \\
\end{array}$ & 0,011 a 0,056 & $\begin{array}{c}\mathrm{y}=4188,5914 \mathrm{x}+0,4940 \\
\mathrm{~F}_{\text {calculado }}(617,3235)>\text { valor } \mathrm{p}\left(2,421 * 10^{-12}\right)\end{array}$ & 0,979 & 0,462 & 0,684 & $\begin{array}{c}\text { Homoscedástico } \\
\text { Significante } \\
\end{array}$ \\
\hline $\begin{array}{l}\text { Tetraclorvinfós } \\
\text { Anova teste F } \\
\text { Anova falta de ajuste } \\
\end{array}$ & 0,01 a 0,051 & $\begin{array}{c}\mathrm{y}=2787,7877 \mathrm{x}+4,9800 \\
\mathrm{~F}_{\text {calculado }}(631,8844)>\text { valor } \mathrm{p}\left(2,087 * 10^{-12}\right)\end{array}$ & 0,980 & 0,457 & 0,684 & $\begin{array}{c}\text { Homoscedástico } \\
\text { Significante } \\
\end{array}$ \\
\hline $\begin{array}{l}\text { Tiometona } \\
\text { Anova teste F } \\
\text { Anova falta de ajuste } \\
\end{array}$ & 0,01 a 0,048 & $\begin{array}{c}\mathrm{y}=5279,9076 \mathrm{x}-1,6444 \\
\mathrm{~F}_{\text {calculado }}(459,5848)>\text { valor } \mathrm{p}\left(1,579 * 10^{-11}\right)\end{array}$ & 0,972 & 0,644 & 0,684 & $\begin{array}{c}\text { Homoscedástico } \\
\text { Significante } \\
\end{array}$ \\
\hline $\begin{array}{l}\text { Triazofós } \\
\text { Anova teste F } \\
\text { Anova falta de ajuste } \\
\end{array}$ & 0,01 a 0,051 & $\begin{array}{c}\mathrm{y}=2508,7874 \mathrm{x}+1,8800 \\
\mathrm{~F}_{\text {calculado }}(643,5612)>\text { valor } \mathrm{p}\left(1,857 * 10^{-12}\right)\end{array}$ & 0,980 & 0,583 & 0,684 & $\begin{array}{c}\text { Homoscedástico } \\
\text { Significante } \\
\end{array}$ \\
\hline $\begin{array}{l}\text { Triazofós } \\
\text { Anova teste F } \\
\text { Anova falta de ajuste } \\
\end{array}$ & 0,01 a 0,051 & $\begin{array}{c}\mathrm{y}=2508,7874 \mathrm{x}+1,8800 \\
\mathrm{~F}_{\text {calculado }}(643,5612)>\text { valor } \mathrm{p}\left(1,857 * 10^{-12}\right)\end{array}$ & 0,980 & 0,583 & 0,684 & $\begin{array}{c}\text { Homoscedástico } \\
\text { Significante } \\
\end{array}$ \\
\hline
\end{tabular}

